NASA Technical Memorandum 106149

AIAA-93-2438

\title{
Effects of Flow-Path Variations on Internal Reversing Flow in a Tailpipe Offtake Configuration for ASTOVL Aircraft
}

Jack G. McArdle and Barbara S. Esker

Lewis Research Center

Cleveland, Ohio

Prepared for the

29th Joint Propulsion Conference and Exhibit cosponsored by the AIAA, SAE, ASME, and ASEE

Monterey, California, June 28-30, 1993 


\title{
OFFTAKE CONFIGURATION FOR ASTOVL AIRCRAFT
}

\author{
Jack G. McArdle and Barbara S. Esker \\ National Aeronautics and Space Administration \\ Lewis Research Center \\ Cleveland, Ohio 44135
}

\begin{abstract}
$\underline{\text { Abstract }}$
A one-third-scale model of a generic tailpipe offtake system for an advanced short takeoff, vertical landing (ASTOVL) aircraft was tested at the NASA Lewis Research Center Powered Lift Facility. The basic model consisted of a tailpipe with a centerbody to form an annulus simulating turbine outflow with no swirl; twin offtake ducts with elbows at the ends to turn the flow to a downward direction; flow control nozzles at the ends of the elbows; and a blind flange at the end of the tailpipe to simulate a closed cruise nozzle. The offtake ductto-tailpipe diameter ratio was 0.74 . Modifications of a generic nature were then made to this basic configuration to measure the effects of flow-path changes on the flow and pressure-loss characteristics. The modifications included adding rounded entrances at the forward edges of the offtake openings, blocking the tailpipe just aft of the openings instead of at the cruise nozzle, changing the location of the openings along the tailpipe, removing the centerbody, and varying the Mach number (flow rate) over a wide range in the tailpipe ahead of the openings by changing the size of the flow control nozzles.

The tests were made with unheated air at tailpipeto-ambient pressure ratios from 1.4 to 5 . Results are presented and compared with performance graphs, totalpressure contour plots, paint streak flow visualization photographs, and a flow-angle probe traverse at the offtake entrance.
\end{abstract}

\section{$\underline{\text { Nomenclature }}$}
A area, in. ${ }^{2}$
D diameter, in.
g constant, $32.174 \mathrm{ft} / \mathrm{sec}^{2}$
L length, in.
M Mach number; for ideal flow

$$
\frac{\mathrm{M}}{\left(1+\frac{\gamma-1}{2} \mathrm{M}^{2}\right)^{3}}=\frac{\mathrm{w}}{\mathrm{AP}} \sqrt{\frac{\mathrm{RT}}{\gamma \mathrm{g}}}
$$

Copyright $@ 1993$ by the American Institute of Aeronautics and Astronautics, Inc. No copyright is asserted in the United States under Title 17, U.S. Code. The U.S. Government has a royalty-free license to exercise all rights under the copyright claimed herein for Governmental purposes.

All other rights are reserved by the copyright owner.
P total pressure, psia

$\mathrm{P}_{\mathrm{std}}$ standard day pressure, 14.696 psia

$\mathrm{PR}$ pressure ratio relative to ambient pressure, $\mathrm{P} / \mathrm{P}_{\mathrm{am}}$

p static pressure, psia

q dynamic pressure, psi

$\mathrm{R}$ gas constant; for air, $\mathrm{R}=53.35 \mathrm{ft} /{ }^{\circ} \mathrm{R}$

$\mathrm{T}$ total temperature, ${ }^{\circ} \mathrm{R}$

$\mathrm{T}_{\text {std }}$ standard day temperature, $518.7^{\circ} \mathrm{R}$

w measured airflow rate, $\mathrm{lb} / \mathrm{sec}$

$\gamma \quad$ ratio of specific heats; for air, $\gamma=1.40$

$\delta \quad$ ratio of pressure to standard day pressure, $\mathrm{P} / \mathrm{P}_{\mathrm{std}}$

$\theta$ ratio of temperature to standard day temperature, $\mathrm{T} / \mathrm{T}_{\text {std }}$

Subscripts

am ambient

ch choked

n offtake nozzle

w wall static pressure

5 tailpipe or annulus station

5A offtake elbow inlet station

5B offtake duct exit or downturn elbow inlet station

5C downturn elbow exit or offtake nozzle inlet station

Note: Station subscripts followed by 1 or 2 refer to a particular offtake side (see Fig. 2).

\section{$\underline{\text { Introduction }}$}

Many programs have been conducted at the NASA Lewis Research Center (LeRC) to advance the technology needed for advanced short takeoff, vertical landing (ASTOVL) aircraft. These programs include analytical and experimental studies of hot gas ingestion, integrated aircraft/propulsion controls, and ducting and nozzles for engine exhaust systems. ${ }^{1-5}$ 
Several proposed ASTOVL powered lift concepts such as that shown in Fig. 1(a) are based on blocking the cruise exhaust nozzle and redirecting the engine gas forward to lift thrusters during landing or hover flight. The lift thrusters could be ejectors, burners, lift nozzles, or gas-coupled lift fans. In every case, the available lift is directly reduced by pressure loss in the tailpipe offtakes and ducts leading to the thrusters. The flow patterns causing pressure loss are known to be very complex.

A one-third-scale generic ASTOVL tailpipe offtake configuration was studied previously both experimentally and analytically. ${ }^{6-7}$ The model (Fig. 1(b)) consisted of a tailpipe with twin elbows, offtake ducts and flow control nozzles; a small ventral nozzle; and a blind flange to simulate a closed cruise nozzle. The offtake duct-to-tailpipe diameter ratio was 0.74 . The flow was split 45 percent to each offtake and 10 percent to the ventral nozzle. The tailpipe Mach number was 0.3 , and the measured pressure loss from the tailpipe to the offtake flow control nozzle was 15.5 percent. Almost all the loss occurred in turning the flow from the tailpipe into and through the elbows. Additional configuration details and experimental results are given in Ref. 6, and preliminary results of the computational fluid dynamics analysis are reported in Ref. 7 .

The present report is concerned with the effects of flow-path configuration changes on flow behavior and pressure loss. The following modifications were incorporated in the model described in the preceding paragraph to form the configuration called the "basic" model for these tests:

(1) Elbows were added to the ends of the offtake ducts to provide a final flow turn to a downward direction.

(2) A centerbody was added to simulate turbine outflow without swirl in a separate-flow exhaust system, or (less rigorously) could simulate mixing plane outflow in a low-bypass-ratio engine.

(3) The ventral opening was closed and faired over at the tailpipe opening.

The following changes were then made singly to this basic model:

(1) The offtake flow control nozzle size was varied to study flow turning at simulated turbine exit Mach numbers from 0.3 to 0.5 (a range of Mach numbers that future engines may have).

(2) Rounded entrances were added to the forward edge of the tailpipe offtake openings to attempt to improve flow into the openings.
(3) Tailpipe blockers were mounted just aft of the tailpipe offtake openings to assess this type of closure (useful with engines having round cruise nozzles).

(4) The centerbody was lengthened to simulate offtakes closer to the turbine exit.

(5) The offtake flow control nozzle size was varied with the centerbody removed to simulate flow into offtakes far aft of the turbine exit at Mach numbers up to 0.35 and to compare performance with Ref. 6 results.

These changes represent, in a generic fashion, some of the practical factors that would be encountered in designing an ASTOVL exhaust system. The study was experimental only-no computational analyses were done. Results and performance comparisons from tests with unheated air are presented as graphs at tailpipe-toambient pressure ratios from 1.4 to 5 , as contour plots of total-pressure distributions at the ends of the offtake ducts, and as flow visualization results from paint streak and flow-angle probe data.

The appendix provides a list of definitions of terms used herein.

\section{Apparatus}

\section{Basic Model}

The basic model tested is shown in Fig. 2(a). It consisted of the model shown in Fig. 1(b) (previously tested and described in Ref. 6) with the centerbody and downturn elbows added and the ventral opening closed. The downturn elbows were canted $15^{\circ}$ inboard to avoid flow impingement on the facility structure. The model was approximately one-third scale, referenced to the size of current military engines.

\section{Flow-Path Configuration Changes}

The devices used to make flow-path configuration changes are illustrated in Figs. 3 to 6 . The devices were installed and tested separately, not in combination.

Rounded entrances at the forward edges of the offtake openings were formed by inserting blocks in the openings of the basic model. The blocks, shown in Fig. 3, reduced the area of the opening approximately 9 percent.

Two types of tailpipe blocker (Fig. 4) were tested. One blocker was flat; the other blocker was formed by two convex-shaped surfaces having the same radius as the tailpipe so that each half of a full-sized blocker could be stowed against the tailpipe wall. 
The centerbody position was changed relative to the offtake openings by inserting a spool in the cylindrical portion of the centerbody. The centerbody and its locations in the tailpipe are shown in Fig. 5.

The tailpipe Mach number was varied by flow control nozzles of different areas. The nozzles (Fig. 6) were mounted on the downturn elbows for some tests and on the offtake ducts for tests without the downturn elbows. The nozzle designated C-3 was an ASME long-radius design; the others were conical convergent nozzles having a $20^{\circ}$ wall angle.

$\underline{\text { Facility }}$

The tests were performed at the Powered Lift Facility (PLF) at NASA Lewis (Fig. 7). The PLF is a thrust stand enclosed by a dome having an inner acoustic liner to reduce noise radiated to the nearby communities. The stand can measure thrust, normal, and side forces up to $10000 \mathrm{lb}$ (or more for large models) and could be fitted with a burner to provide heated air at the model inlet. The PLF is supplied with pressurized air from the laboratory central system.

\section{$\underline{\text { Instrumentation and Data }}$}

The station locations and flow-path pressure instrumentation are shown in Fig. 2. Pressure rakes were always the same in both offtake sides to avoid flow unbalance. The flow total temperature was measured by stream thermocouples in the 24-in. ducting near the model inlet. The airflow was measured by a facility ASME nozzle in the air supply line.

A traversing flow-angle probe with a five-port sensing tip (same as in Ref. 6) was used to measure flowstream angles, stream total pressure, and stream Mach number at an offtake opening. The probe was calibrated in an open jet at Mach numbers of $0.3,0.5$, and 0.8 over ranges of angles greater than those encountered in the flow pattern tests.

After airflow became steady, data were recorded on a facility computer which scanned all the instrumentation once per second. The performance parameters were computed off-line from data averaged over 10 scans. Discrete values of the total pressure at the various flowpath stations were obtained by averaging rake data, including boundary layer rakes where available. Except for flow-angle probe results, the Mach numbers given in this report are average stream values computed from measured airflow, total temperature and pressure, and geometric flow area.

\section{Procedure}

The model inlet pressure was varied by adjusting a valve in the facility inlet line. Steady-state performance data using unheated air were taken at selected tailpipeto-ambient pressure ratios from 1.4 to 5 . A mainframe computer was used to compute performance parameters off-line from averaged data.

Flow patterns were determined from a probe traverse on the horizontal centerline of the offtake opening on side 2 and from paint streaks in the offtake and downturn elbows. The traverse was made with a fiveport, flow-angle probe as described in Ref. 6. Paint streaks were obtained by applying dabs of thick oily paint on the duct walls, starting airflow quickly, then shutting down quickly after a 1-min hold. The resulting streaks were photographed for record, then redrawn on a plastic mockup of the model for many of the illustrations in this report.

\section{$\underline{\text { Results and Discussion }}$}

The performance of the basic configuration over a range of tailpipe-to-ambient pressure ratios $\mathrm{PR}_{5}$ and airflow rates is presented in this section in terms of several flow and pressure-loss parameters. The effects of flow-path configuration changes are then shown as changes to the most important parameters. Last, flow patterns in the offtake and downturn elbows are described with photographs of flow visualization paint streaks and total-pressure contour plots.

\section{Performance of Basic Model}

The basic model represents an offtake configuration with openings close to the turbine discharge of a separate-flow engine or the mixing plane of a lowbypass-ratio engine: flow swirl was not simulated. The model tailpipe pressure $\mathrm{P}_{5}$ was measured in the cylindrical annulus surrounding the centerbody. The performance of the basic model is shown in Fig. 8 for three offtake nozzle sizes and $\mathrm{PR}_{5}$ 's up to 5 . Each of the performance parameters increased with increasing $\mathrm{PR}_{5}$ until the offtake nozzles choked, after which they remained almost constant. Most of the pressure loss occurred between the tailpipe and the end of the offtake duct, Station 5B. It was shown in Ref. 6 that almost all the loss up to Station 5B occurred in turning the flow from the tailpipe into and through the offtake elbows with only a relatively small loss (such as from wall friction) in the long straight ducts. Presumably, the same behavior took place in the basic model; in addition, a 
measurable loss occurred as the air flowed through the downturn elbows. The distribution of losses in the model when the offtake nozzles were choked is shown in Fig. 9. The graph is labeled to show the loss in the downturn elbows both as a percentage of tailpipe pressure and as a fraction of the dynamic pressure at the elbow entrance $\mathrm{q}_{5 \mathrm{~B}}$. The latter data are consistent with values reported in Ref. 8 for the same type of elbows with no inlet pressure distortion. For the model tested, the pressure drop to the flow control nozzles increased nonlinearly with annulus flow or Mach number and reached as high as 27 percent at Mach 0.48 . This is considered a large loss because it would reduce the maximum thrust obtainable from a lift thruster by about the same amount.

\section{Performance with Flow-Path Configuration Changes to Basic Model}

The large penalty from pressure drop in the basic model was motivation for trying to improve performance with generic modifications to the existing hardware. Results of tests with the modified model are presented in this section.

Rounded offtake entrances. Insert blocks were installed at the front edges of the offtake openings to form rounded entrances (see Fig. 3). The results of this change to the basic model with the C-3 and C-4 offtake nozzles are shown in Fig. 10. With or without the inserts, the trends of the pressure losses with $\mathrm{PR}_{5}$ are the same although the inserts reduced the flow capacity and raised the pressure loss slightly. In tests of a ventral nozzle, ${ }^{3}$ a rounded entrance reduced the turning pressure loss by $4 \frac{1}{2}$ percentage points. The same reduction did not occur in the offtake model because the flow was turned through a larger angle in the elbow than in the ventral duct, and the flow was separated from the inboard side of the elbow wall for a longer flow distance. The blocks chosen did not influence the flow pattern in this already-separated region.

Tailpipe blockers. The term "blocker" as used in this paper refers to a tailpipe closure that is located near the offtake openings as opposed to a closed cruise nozzle at the end of the tailpipe. Two blockers (Fig. 4) were tested in the basic model using the C-3 nozzles. The results are presented in Fig. 11. Both blockers decreased the pressure loss and increased the flow capacity. The shaped blocker reduced the offtake pressure loss by 6 percentage points and increased the flow capacity almost 9 percent. The improvements were not as great with the flat blocker. The changes are attributed to the elimination of the flow recirculation region in the unblocked tailpipe and the addition of direct flow guidance into the openings provided by the blocker surface.
Location of openings. The effects on performance of locating the offtake openings at various stations along the tailpipe were studied in three tests. Starting with the basic model, moving the openings closer to the turbine was simulated by extending the centerbody (see Fig. 5 ). Locating the openings far downstream from the corebypass mixing plane was simulated by removing the centerbody hardware to increase the flow area ahead of the offtake openings.

The results of these tests are given in Fig. 12. Moving the openings closer to the turbine by lengthening the centerbody did not alter the performance from the basic model. However, moving the openings downstream away from the turbine by removing the centerbody increased the flow capacity by 4 percent and reduced the pressure loss by $21 / 2$ percentage points. These improvements are similar when the results are compared at the same $\mathrm{PR}_{5}$ or tailpipe flow rate (Figs. 12(b) and (c)). With regard to performance, these tests demonstrate that the best place for offtake openings is far aft of the turbine exit where flow is uniform and the Mach number is low (assuming a negligible totalpressure loss caused by the centerbody tailcone). A blocker, instead of a closed cruise nozzle, may reduce the pressure loss further, but that configuration was not tested.

Without centerbody. The effect of the tailpipe Mach number on performance was studied for offtake openings located far from the turbine. For these tests the centerbody and downturn elbows were removed from the basic model, making the model shown in Fig. 1(b) without the ventral nozzle.

The test results are presented in Fig. 13. With the offtake nozzles choked, the tailpipe Mach number ranged from about 0.20 to 0.35 ; the offtake duct Mach number was as high as 0.48. These Mach numbers are near the maximum obtainable for the geometry sizes used in the model tested because the largest (C-5) offtake nozzle contraction was very small (Fig. 6).

The pressure loss from the tailpipe to the ends of the offtake ducts (no final turn elbows were used) is shown in Fig. 14. The loss is plotted against both Mach number and airflow for cases with and without the centerbody. Losses increased nonlinearly with Mach number but were highly dependent on the area at which they were calculated. The results are better correlated with the referred tailpipe flow rate as shown in Fig. 14(b). However, the pressure drop must also be dependent on the effective tailpipe-to-offtake duct area ratio (not varied with this model) so the numerical data in this figure do not apply to all offtake geometries, although the trends should be very similar. 


\section{Flow Patterns}

Wall flow patterns in and around the offtake openings and in a downturn elbow in the basic model with C-3 offtake nozzles were obtained from flow visualization paint streaks. This section also presents the results of a flow-angle probe traverse at an offtake opening and total-pressure contour plots of the flow leaving a downturn elbow.

Flow visualization. Figure 15(a), a view from the blocked end of the tailpipe, shows the arrangement of instrumentation and hardware near the offtake openings which might have affected the flow patterns (also see Fig. 2).

Figure 15(b) shows the flow pattern at the offtake opening. Flow upwash (from the bottom toward the top of the tailpipe) is evident from streaks on the centerbody tailcone and on the wall ahead of the opening. The upwash could be an effect of the flow entering the offtakes or could have been caused by nonuniform flow at Station 5. Flow nonuniformity is believed to be minimal for two reasons. First, the centerbody, flow straighteners, and boundary layer trips all were concentrically mounted on accurately machined surfaces to avoid nonuniformity from malalignment. Second, the nonuniformity from total-pressure distortion measured by rakes at Station 5 typically was less than 0.5 percent. (The whole distortion probably was somewhat higher because the rakes were not positioned to detect distortion caused by wakes from the three centerbody support struts; also, there was some additional distortion from the rakes themselves.) Upwash streaks on the tailcone lead to swirls called "spiral nodes," which denote separation points for vortical flow leaving the surface. The nodes were the same size and in the same position on both sides of the tailcone but had opposite rotation. Although the vortical flow paths were not determined, it is likely that the vortices entered the offtake openings and mixed with other offtake flow.

Photographs of flow visualization streaks drawn on a scale mockup of the model are presented in Fig. 16. In Fig. 16(a) the tailpipe is cut in half on its plane of symmetry. The streaks on the tailpipe wall show that flow from the lower part of the tailpipe followed the upwash direction into the offtake openings. Flow from the upper part of the tailpipe tended to swirl (in a clockwise manner in Fig. 16(a)) as it entered the opening. This largescale swirl was opposite in rotation to the vortex from the spiral node on the tailcone. The upwash, large-scale swirl, and vortices all seem to be related and interacting, but the basic cause or triggering mechanism was not found.
Streaks on the offtake elbow walls are shown in Figs. 16(b) and (c). Some of the offtake flow followed the outer wall of the elbow, but the streaks also show the large-scale swirling flow that cut across the lower part of the elbow without following the wall curvature. The swirl is counterclockwise in direction (looking upstream) at the end of the offtake elbow (Fig. 16(c)). This pattern is very similar to the pattern found in the same configuration without the centerbody (reported in Ref. 6).

Paint streaks on the downturn elbow in side 2 (Fig. 2) are shown in Fig. 17. The streaks showed (Figs. 17(a) and (b)) that the incoming flow had the same counterclockwise swirl previously noted at the end of the offtake elbow. The flow turned through the elbow toward the inside wall without following the surface curvature, probably being influenced by the incoming swirl.

On the inner half of the elbow (Fig. 17(c)) the streaks showed that the flow was drawn toward the inside wall at the end of the elbow (locale of lowest static pressure). The flow then turned as necessary to exit through the nozzle. Altogether, the streaks in the downturn elbow indicated a flow pattern expected from classical fluid dynamic principles: Two secondary flows became superimposed on the bulk flow in the elbow, with each secondary flow moving fluid along the wall from the outer to inner surfaces, then returning by centrifugal action to the outer surface. For the case shown herein, this classical pattern was distorted slightly by the incoming swirl.

Flow traverse. A calibrated flow-angle probe and a technique described in Ref. 6 were used to make a traverse on the horizontal centerline at Station $5 \mathrm{~A}$ of the basic model. The results of the traverse are shown in Fig. 18 along with the results of a similar traverse in the same model with no centerbody. ${ }^{6}$ The total-pressure ratio (Fig. 18(a)) is the ratio of the computed probe total pressure to $P_{5}$. The total-pressure ratio and the computed stream Mach number (Fig. 18(b)) both were higher in the aft part of the offtake opening of the basic model than in the test without the centerbody. In both tests, the pressure and Mach number fell off rapidly in the turning flow at the front edge of the opening. The measured total-pressure distortion from these data was over 40 percent.

The angles at which the flow entered the opening are called the approach angle and the swirl angle (see the appendix for definitions). These measured angles are shown in Figs. 18(c) and (d), respectively. In both tests the variations along the traverse path are similar. The flow had begun to turn in the tailpipe, as indicated by 
the approach angle results. The flow swirled downward in the aft part of the opening and upward in the central and front parts. The same large-scale swirl can be seen in the paint streaks on the wall in Fig. 16(a). All the probe data were smooth and continuous across the traverse, indicating that the vortex anchored on the centerbody tailcone did not flow through the offtake centerline.

Pressure contours. Total-pressure contours measured by rakes at Station 5C (Fig. 2(b)) are given in Fig. 19. The data are for the basic configuration with three different choked flow control nozzles. As noted in the figure subtitles, the distortion levels at the end of the long, straight offtake ducts (Station 5B) rose with the flow rate, reaching 7.9 percent for the highest flow. In the downturn elbows the flow tended to concentrate on the outside wall, and the pressure was a little higher on the side coming from the outside of the offtake elbow. As expected, the total-pressure gradients and distortion levels increased with the flow rate. At the highest flow rate, the distortion at the downturn elbow exit was 19.2 percent (Fig. 19(c)), caused primarily by a relatively small region of lower pressure near the inside wall.

\section{Summary of Results}

A one-third-scale model generic ASTOVL exhaust system was tested with unheated air at tailpipe-toambient pressure ratios from 1.4 to 5 to measure the pressure loss and other flow characteristics. The model consisted of a tailpipe with a centerbody to form an annulus simulating turbine outflow, twin offtake ducts with elbows at the ends to turn the flow to a downward direction, flow control nozzles at the ends of the elbows, and a blind flange at the end of the tailpipe to simulate a closed cruise nozzle. The airflow rate was varied by changing the size of the flow control nozzles. Modifications then were made to this basic configuration to determine the effects of flow-path changes on the flow characteristics. The important results are as follows:

1. For all the configurations tested, the offtake pressure loss and other flow parameters were constant at pressure ratios or flow rates greater than those needed to choke the flow control nozzles.

2. For the basic model after choked flow, the offtake pressure loss up to the entrance of the downwardpointing elbows increased nonlinearly with the annulus Mach number (or, alternatively, with the total airflow referred to annulus conditions). An additional loss, about $0.25 \mathrm{q}$, occurred in the downward pointing elbow, where $q$ is the dynamic pressure at the elbow entrance.
The total offtake system loss varied from 11 percent at a Mach number of 0.29 to 27 percent of the annulus total pressure at a. Mach number of 0.48 .

a. At an annulus Mach number of about 0.42 , the offtake pressure loss was reduced by 6 percentage points when a shaped tailpipe blocker was mounted just aft of the offtake openings. The blocker also raised the flow capacity of the system almost 9 percent, apparently by guiding the flow into the openings. A flat blocker also reduced the pressure loss and raised the flow capacity but did so to a lesser extent.

b. The pressure loss and flow capacity were not changed significantly when rounded entrances were added to the front of the tailpipe offtake openings or when the openings were located closer to the centerbody tailcone.

c. The centerbody was removed from the basic configuration to increase the tailpipe flow area ahead of the offtake openings, as though the openings were far aft of the turbine exit. Compared with the basic configuration, the offtake pressure loss was reduced about 3 percentage points for the same flow rate. The offtake pressure loss increased nonlinearly with the tailpipe Mach number.

3. Flow visualization paint streaks at an offtake opening in the tailpipe of the basic configuration revealed flow upwash leading to spiral nodes on the centerbody tailcone. The paths of the vortical flow leaving the spiral nodes were not determined. Other paint streaks and a flow-angle probe traverse at the opening showed a large-scale swirl in the flow entering the offtake, in a manner similar to flow patterns previously reported in a model without a centerbody. The totalpressure gradient in the offtake flow was large at the offtake elbow but typically was reduced to only about 5 percent distortion at the ends of the long offtake ducts. The large-scale swirl persisted in the flow through the ducts.

4. Flow visualization paint streaks in a downturn elbow showed that a secondary flow pattern expected from classical fluid dynamics was superimposed on the bulk flow although the secondary pattern was distorted slightly because of the flow swirl entering the elbow.

\section{Appendix-Definitions}

Approach angle

Angle between the flow vector and the tailpipe centerline measured in a horizontal plane 


\section{Distortion}

Difference between maximum and minimum total pressure, measured by rake tubes outside the boundary layer, all divided by average total pressure

Swirl angle

Angle between the flow vector and the offtake centerline measured in a plane normal to the traverse path

\section{$\underline{\text { References }}$}

1. Smith, C.F., and McArdle, J.G., "Flow in a Ventral Nozzle for Short Takeoff and Vertical Landing Aircraft," Journal of Propulsion and Power, Vol. 8, No. 2, Mar.-Apr. 1992, pp. 530-536.

2. McArdle, J.G., and Smith, C.F., "Experimental and Analytical Study of Close-Coupled Ventral Nozzles for ASTOVL Aircraft, "NASA TM-103170, 1990.

3. Esker, B.S., and McArdle, J.G., "Performance Characteristics of a One-Third Scale Vectorable Ventral Nozzle for ASTOVL Aircraft," AIAA Paper 90-2271, July 1990.
4. McArdle, J.G., and Esker, B.S., "Performance Characteristics of a Variable-Area Vane Nozzle for Vectoring an ASTOVL Exhaust Jet up to $45^{\circ}$," AIAA Paper, 93-2437, June 1993.

5. Esker, B.S., and McArdle, J.G., "Experimental Performance of a Ventral Nozzle with Pitch and Yaw Vectoring Capability for ASTOVL Aircraft," NASA TM-106054, 1993.

6. McArdle, J.G., Esker, B.S., and Rhodes, J.A., "Internal Reversing Flow in a Tailpipe Offtake Configuration for ASTOVL Aircraft," AIAA-92-3790, July 1992.

7. Rhodes, J.A., Esker, B.S., and Smith, C.F., "Computational and Experimental Investigation of Subsonic Internal Reversing Flows," AIAA-92-3791, July 1992.

8. Higginbotham, J.T., Wood, C.C., and Valentine, E.F., "A Study of the High-Speed Performance Characteristics of $90^{\circ}$ Bends in Circular Ducts," NACA TN3696, 1956. 


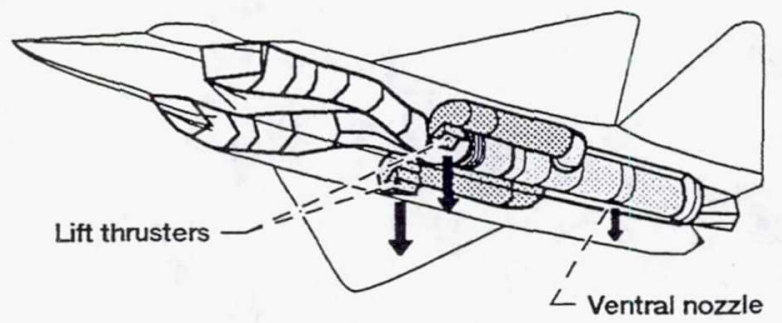

(a) ASTOVL aircraft.
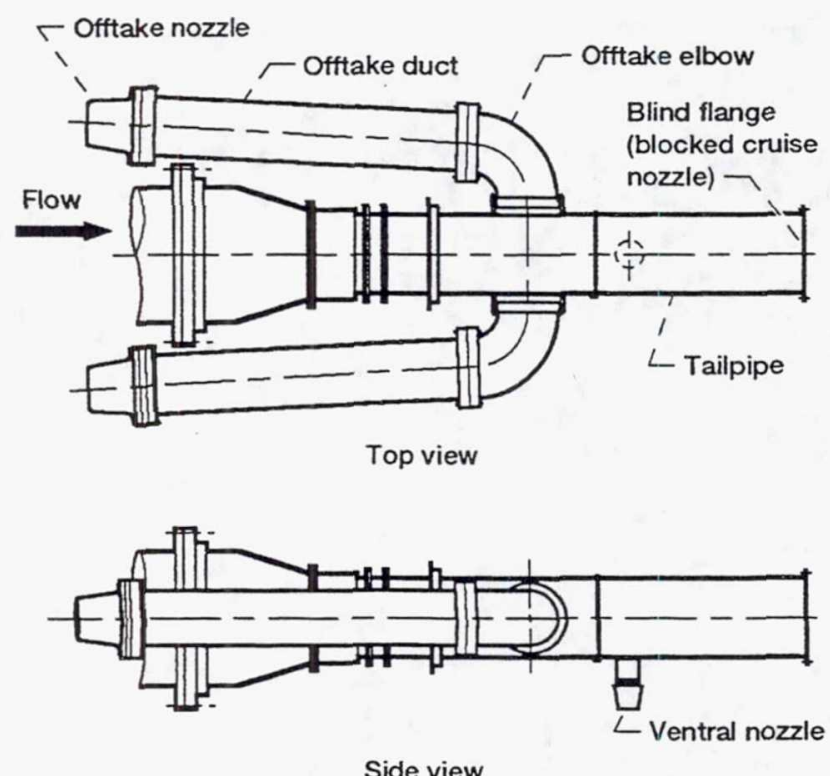

(b) Model tested in reference 6 (no lift thrusters).

Fig. 1.-ASTOVL powered lift system using engine exhaust gas. 


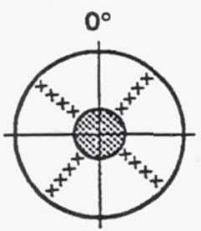

Station 5

Tailpipe (annulus with centerbody)

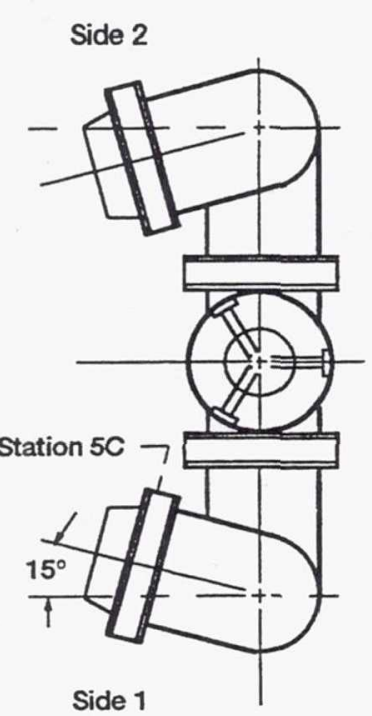

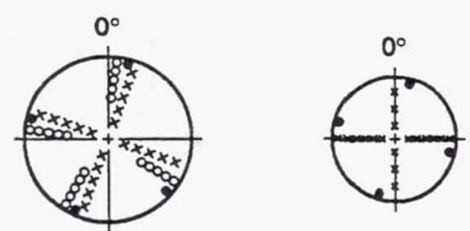

Station 5

Tailpipe (without centerbody)

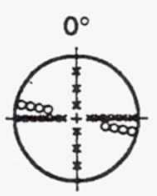

Station 5B1, 5B2

Duct exit $\times$ Stream total pressure, center of equal area

- Boundary layer total pressure

- Wall static pressure
Station $5 \mathrm{C1}, 5 \mathrm{C2}$

Nozzle inlet

and downtum elbow exit

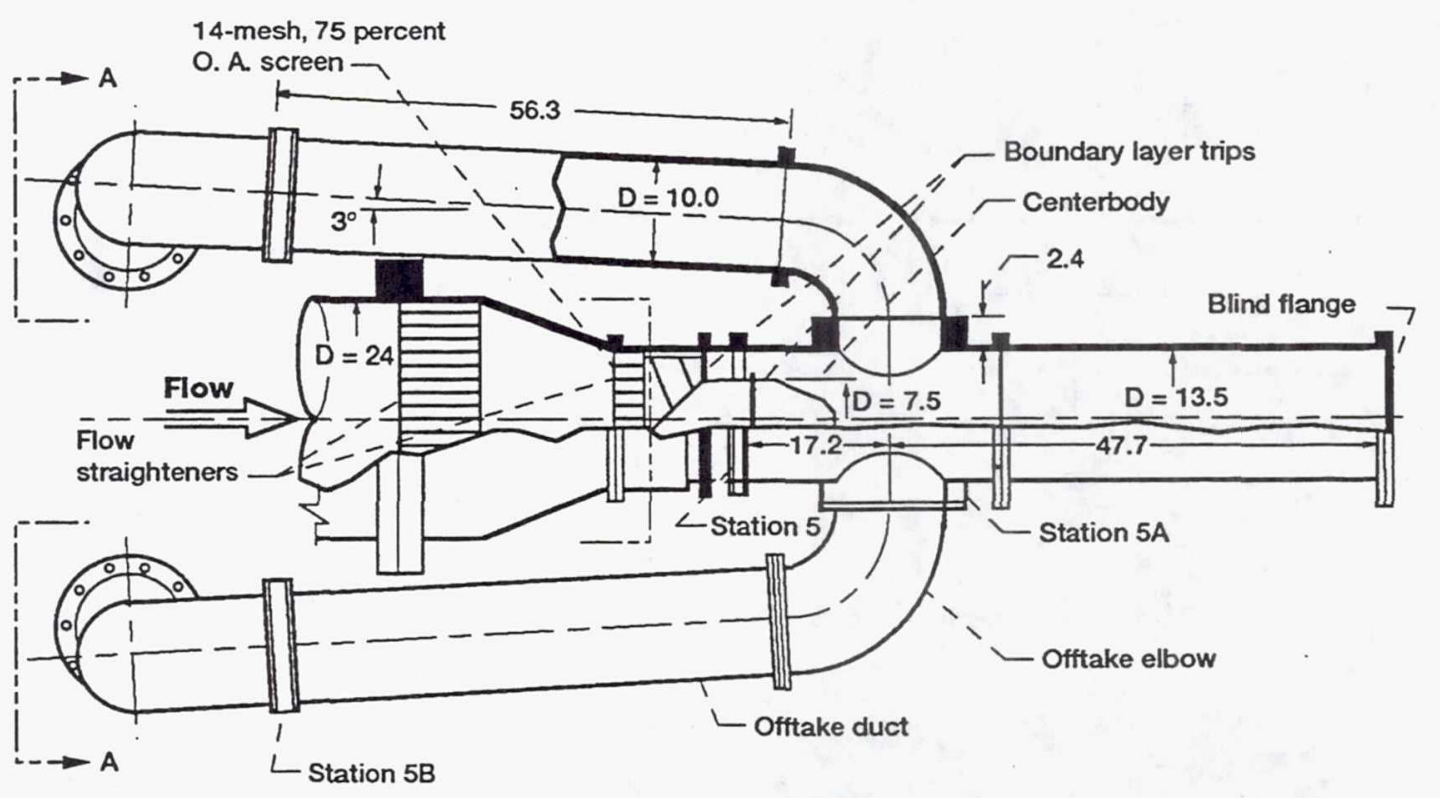

View A-A

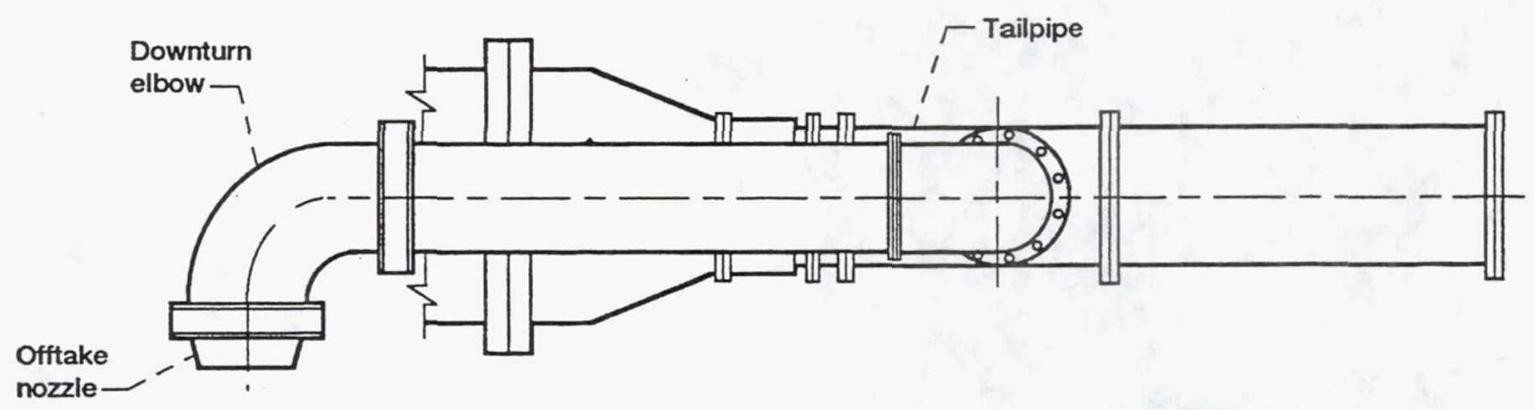

Figure 2.-Basic model tested showing station locations and instrumentation. Station cross sections drawn looking into flow with $0^{\circ}$ on top. All dimensions are in inches. 


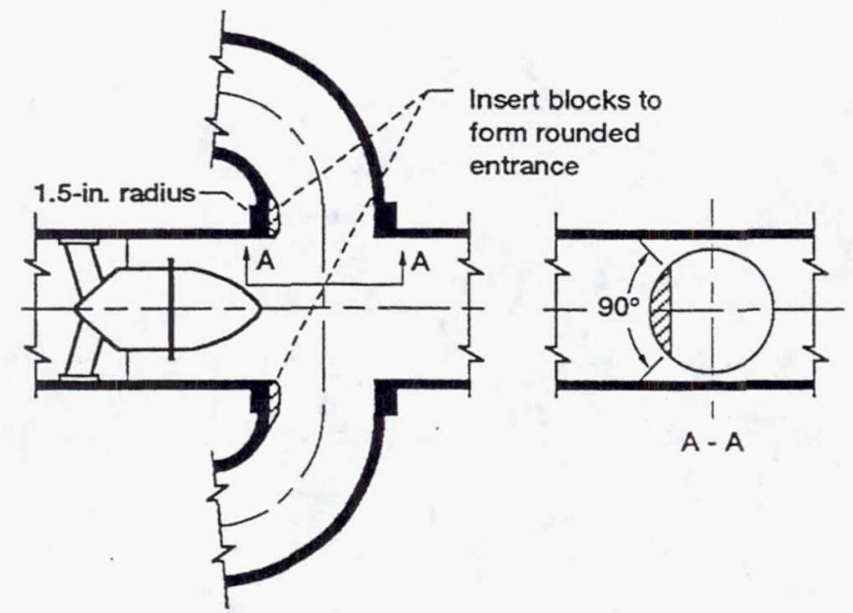

(a) Insert block size and location.

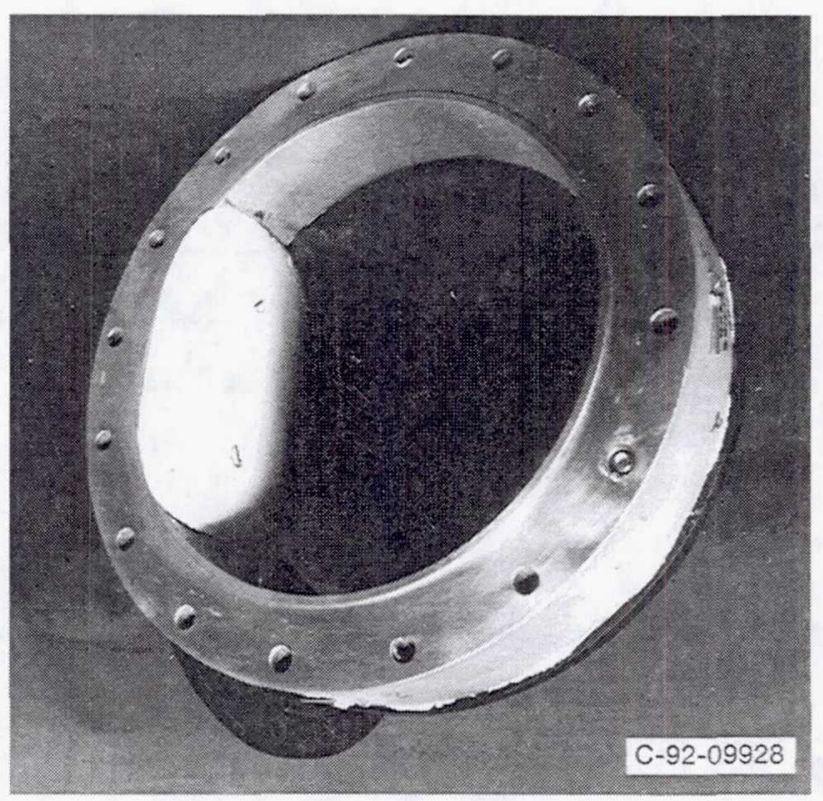

(b) Insert block installed on model.

Figure 3.-Rounded entrances at forward edges of offtake openings.

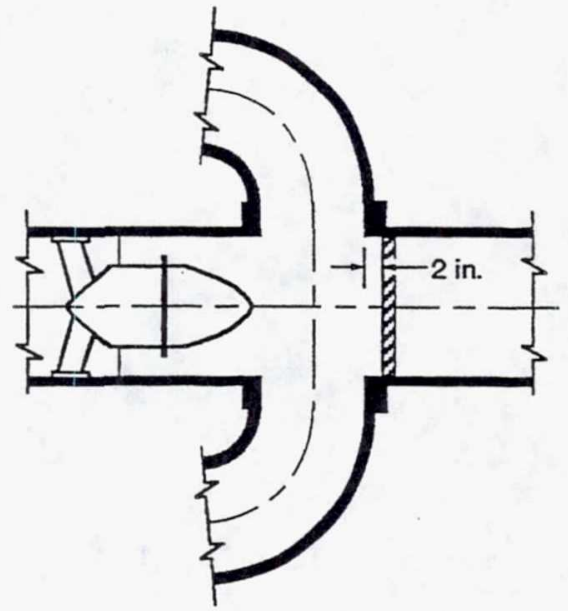

(a) Flat blocker.

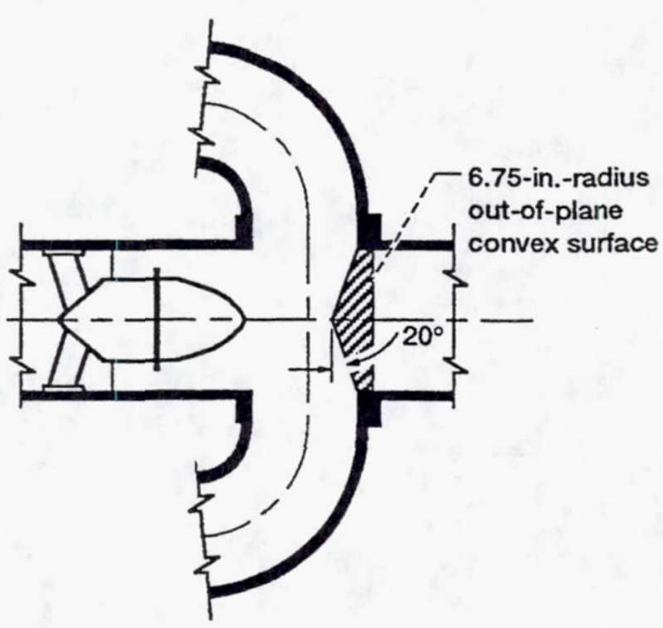

(b) Shaped blocker.

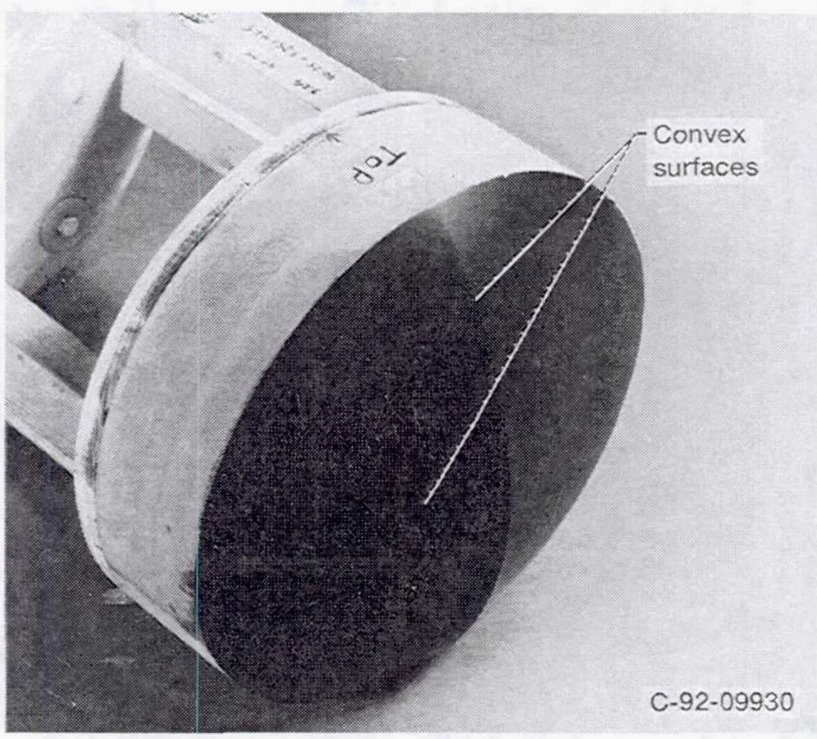

(c) Shaped blocker.

Figure 4.-Tailpipe blockers mounted just aft of offtake openings. 


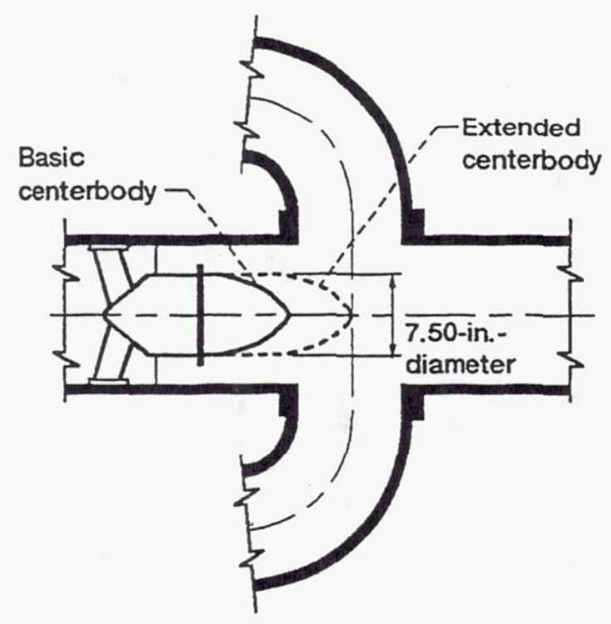

(a) Centerbody size and location.

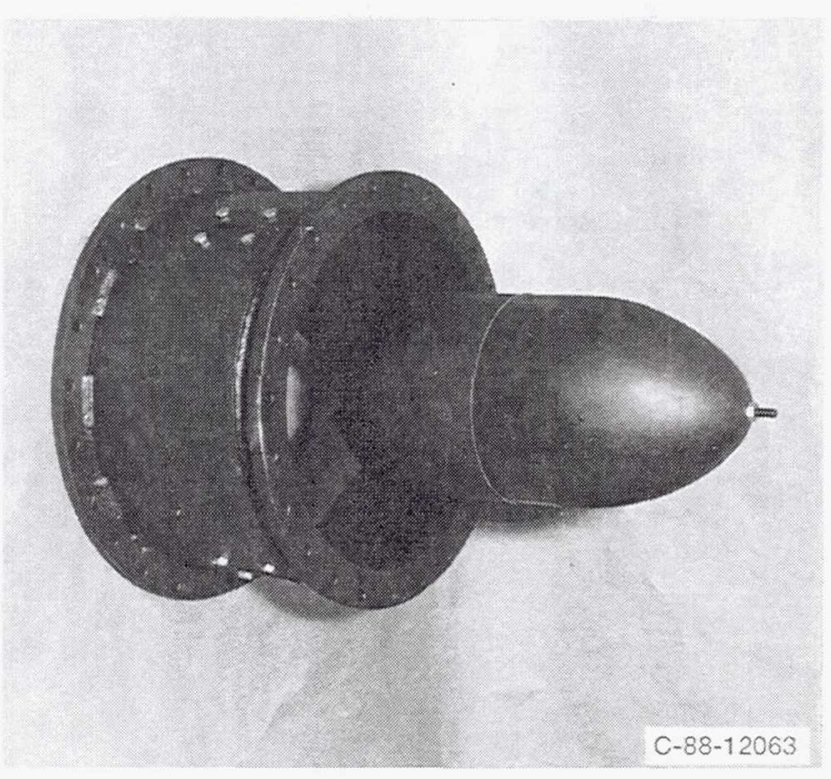

(b) Basic centerbody mounted in tailpipe.

Figure 5.-Centerbody used to simulate turbine outflow.
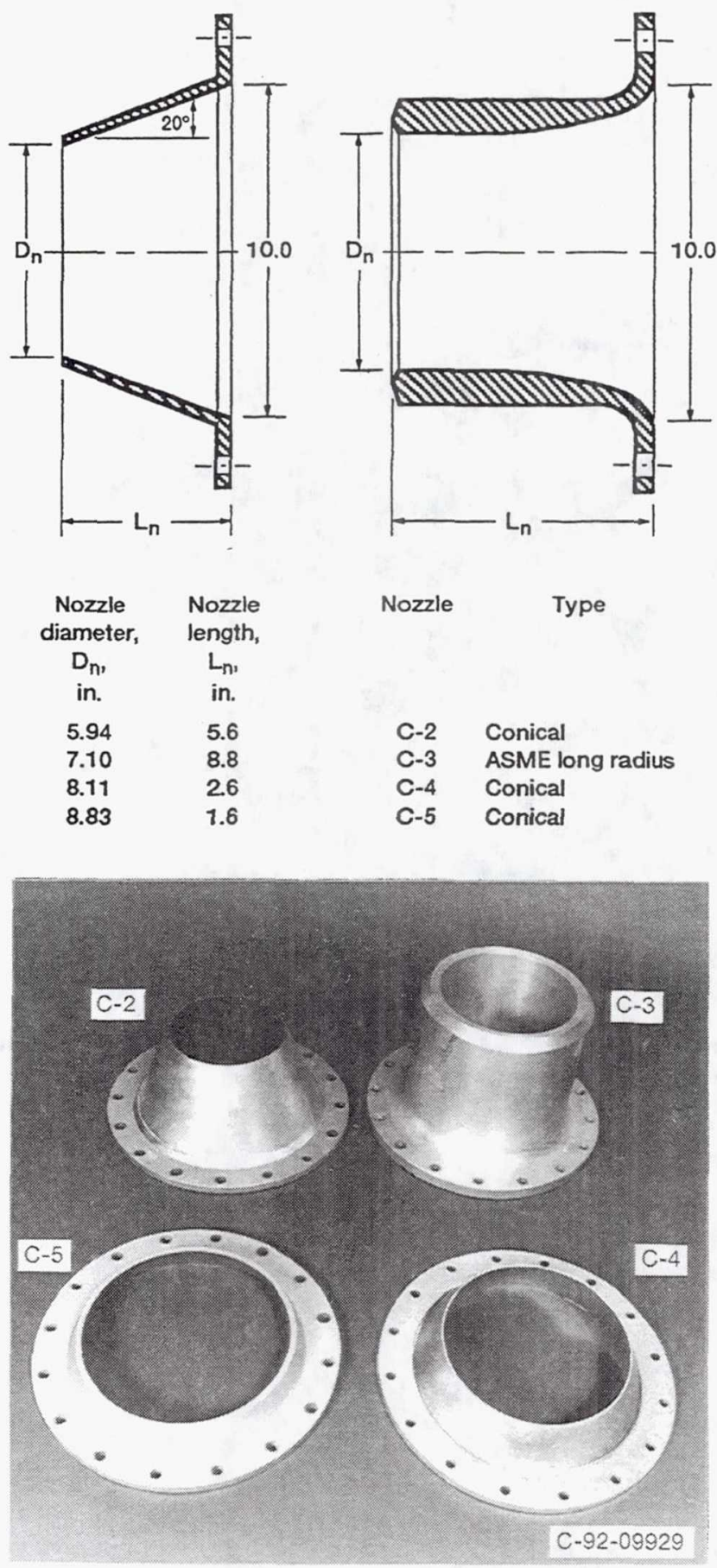

Figure 6.-Flow control offtake nozzles. 


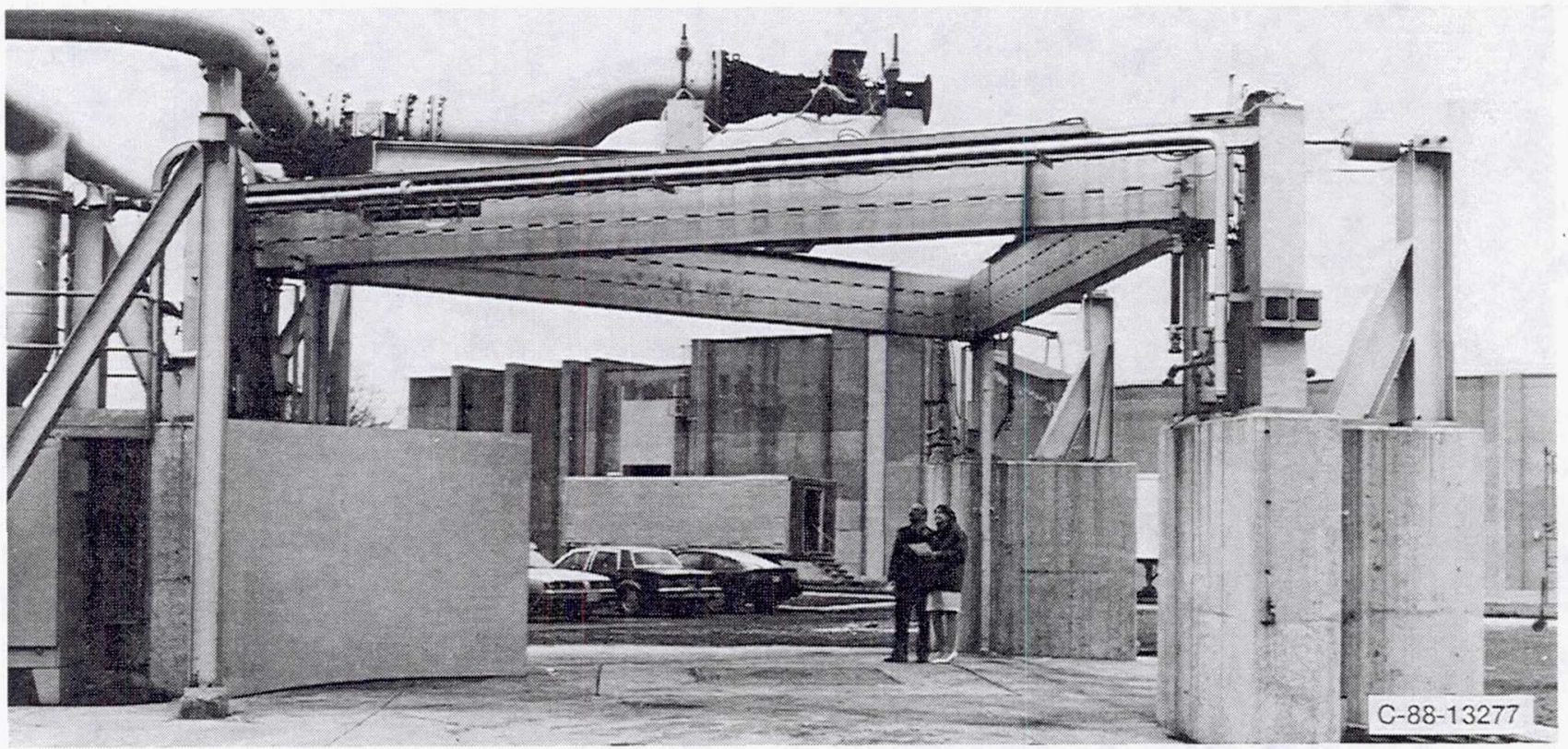

Figure 7.-Powered Lift Facility. (Since this photograph was taken, the facility has been enclosed in an acoustic dome.) 


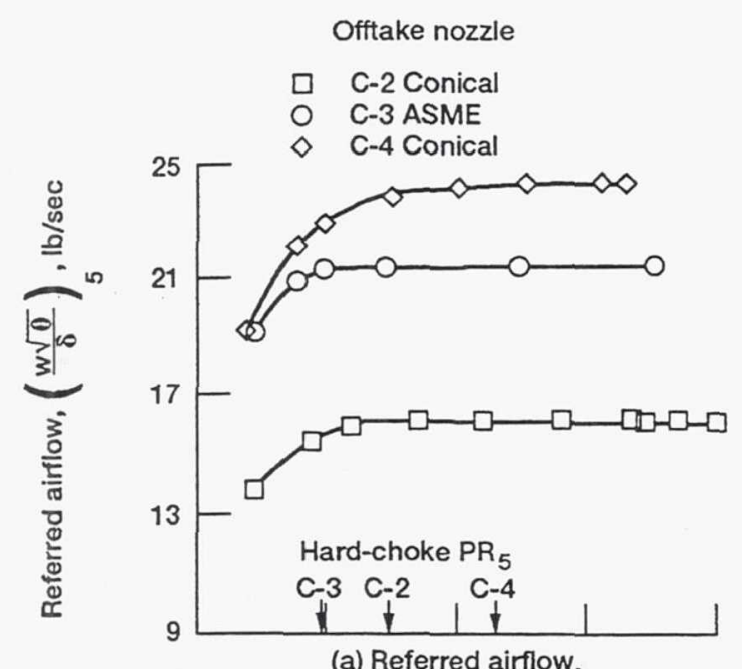

(a) Referred airflow.

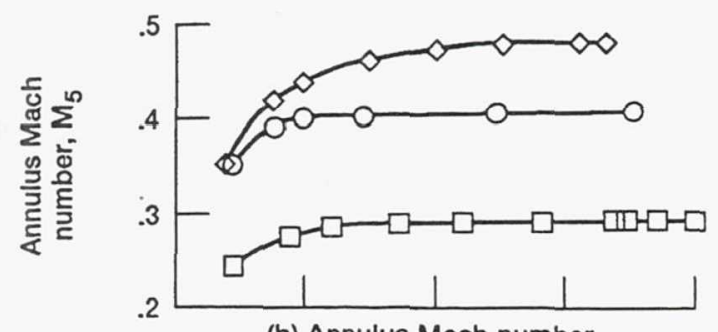

(b) Annulus Mach number.

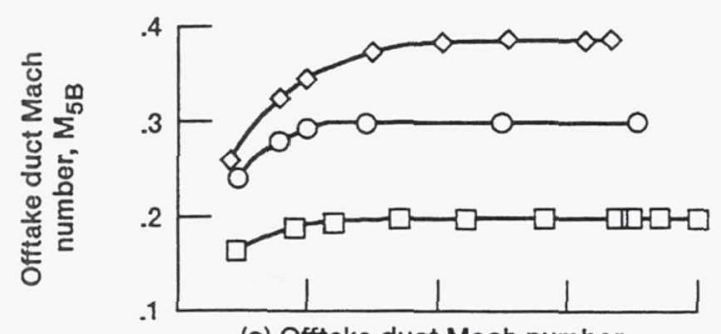

(c) Offtake duct Mach number.

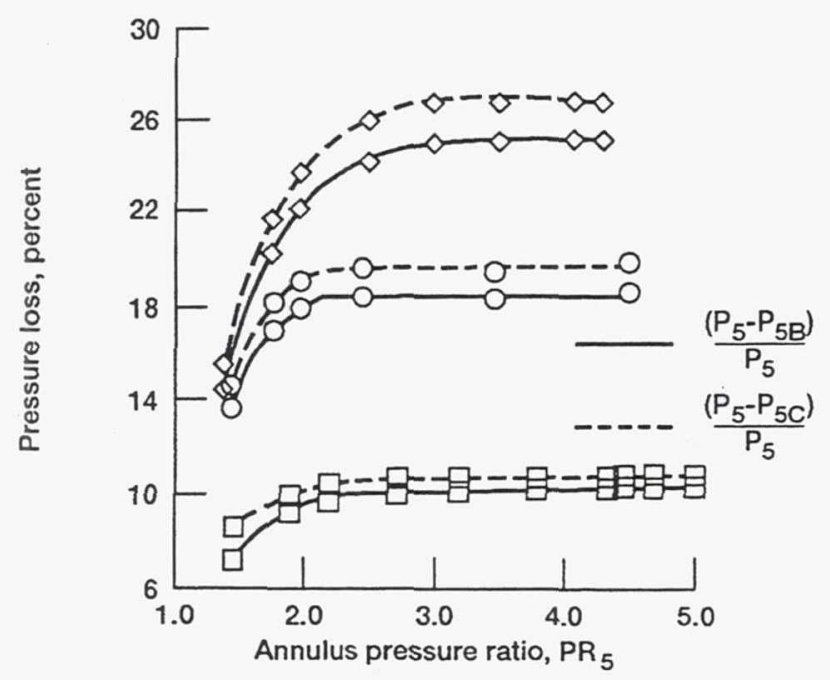

(d) Pressure loss.

Figure 8.-Performance of basic model.

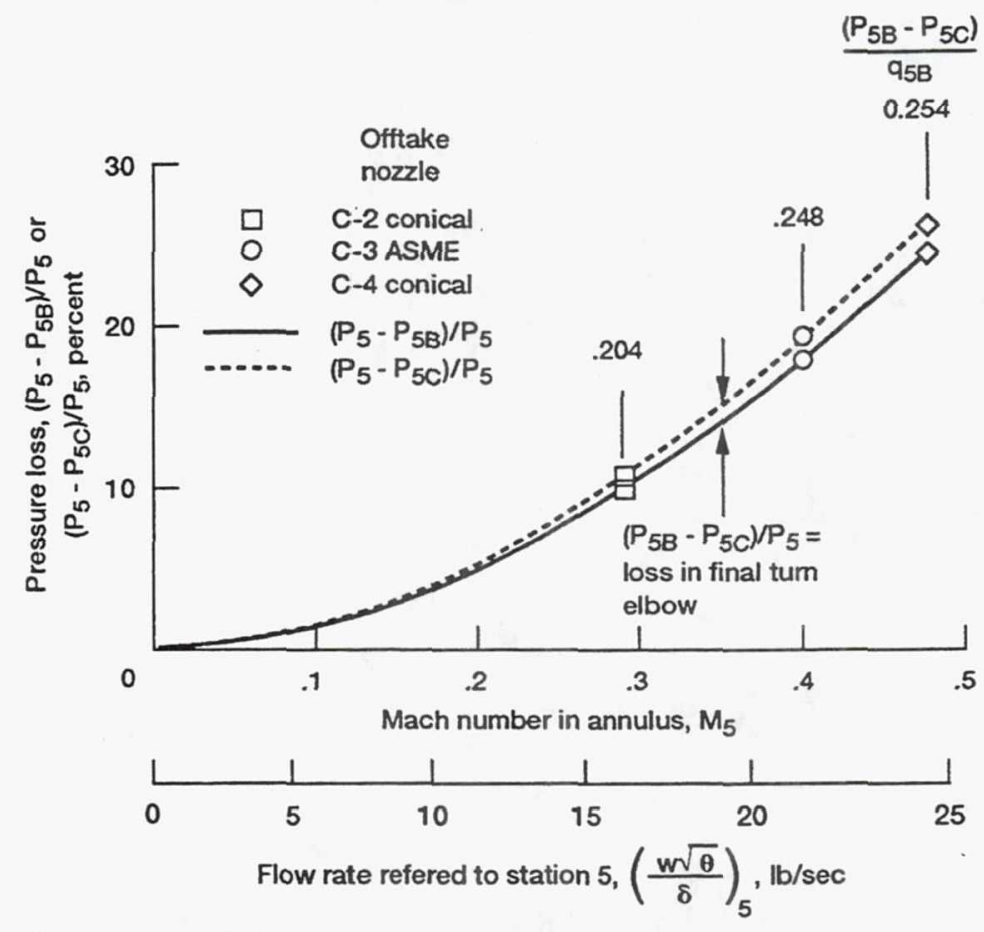

Figure 9.-Distribution of losses for basic configuration with choked offtake nozzles. 


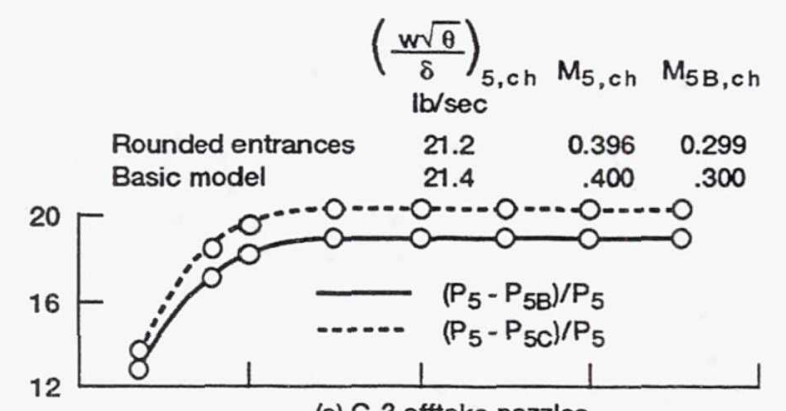

(a) C-3 offtake nozzles.

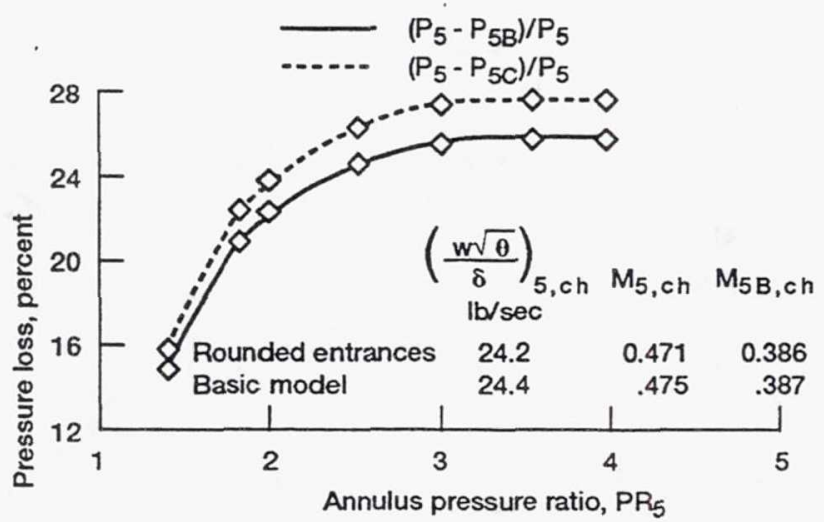

(b) C-4 offtake nozzles.

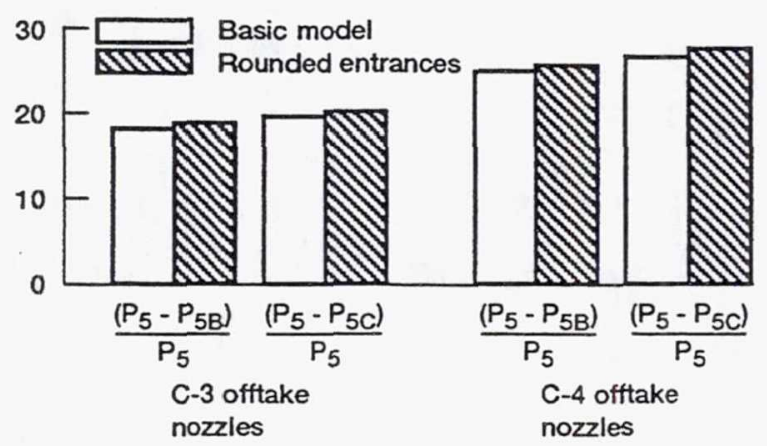

(c) Comparative losses for choked offtake nozzles.

Figure 10.-Effect of rounded entrances on pressure losses.

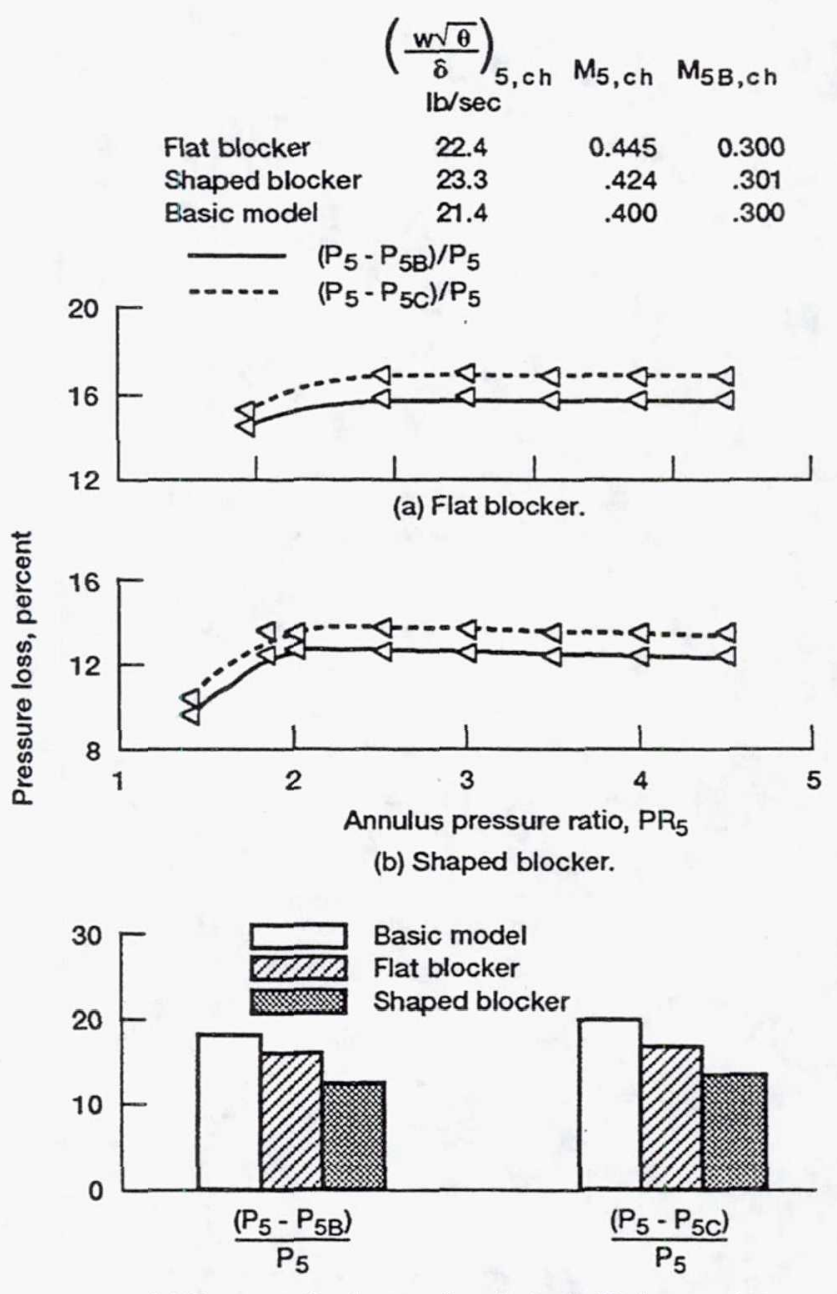

(c) Comparative losses for choked offtake nozzles.

Figure 11.-Effect of tailpipe blockers on pressure losses with C-3 offtake nozzles. 


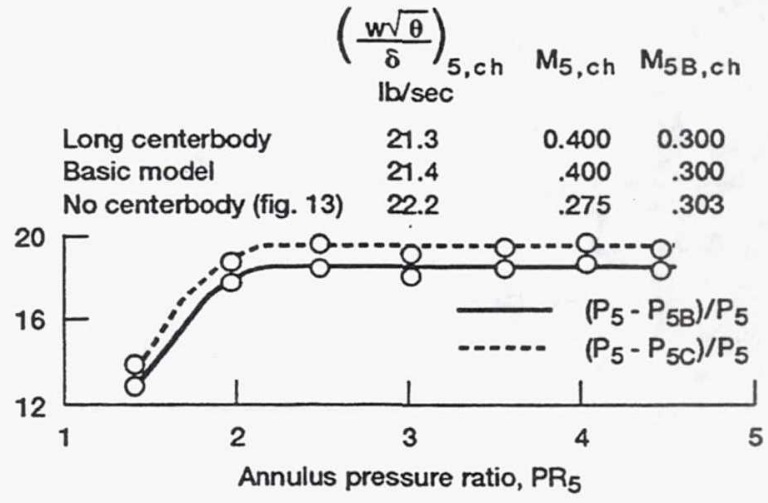

(a) Long centerbody.

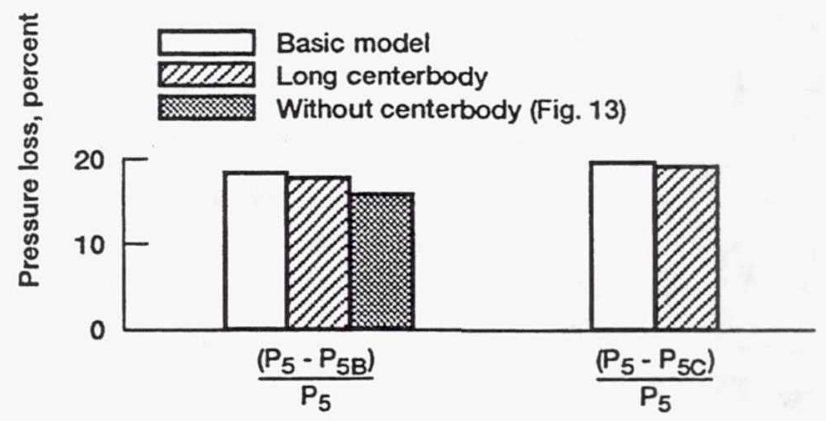

(b) Loss with choked offtake nozzles.

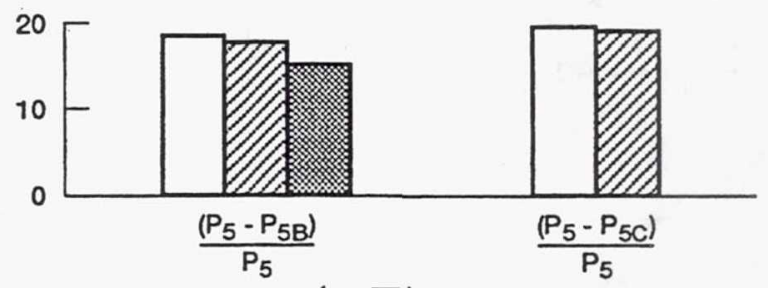

(c) Loss at $\left(\frac{w \sqrt{\theta}}{\delta}\right)_{5, \mathrm{ch}}=21.3 \mathrm{lb} / \mathrm{sec}$.

Figure 12.-Effect of offtake position on pressure loss with C-3 offtake nozzles. 


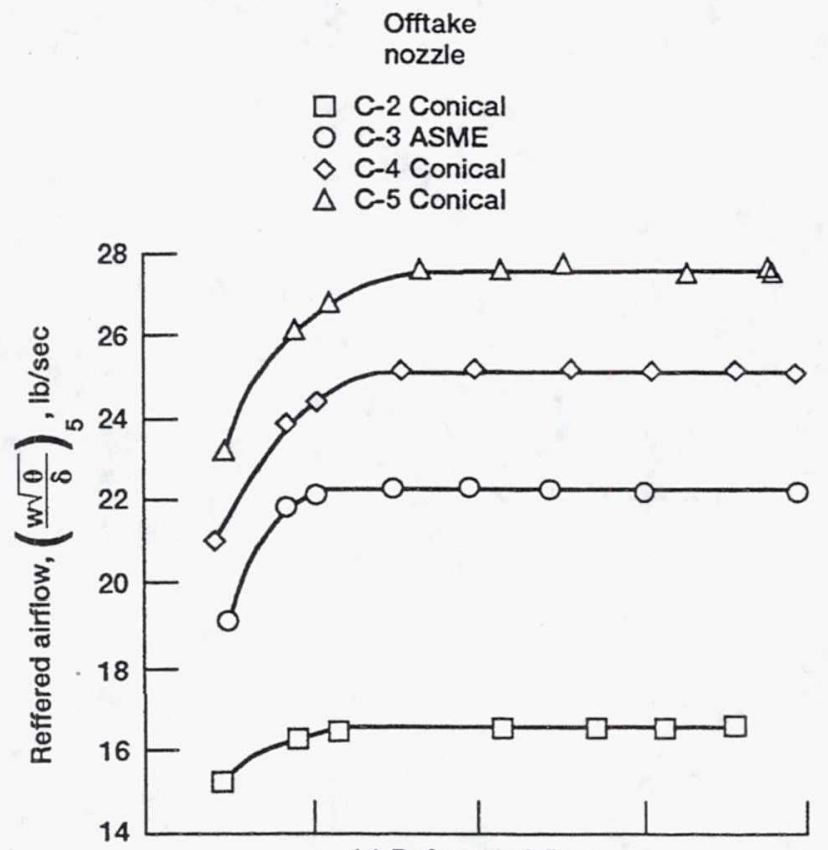

(a) Referred airflow.

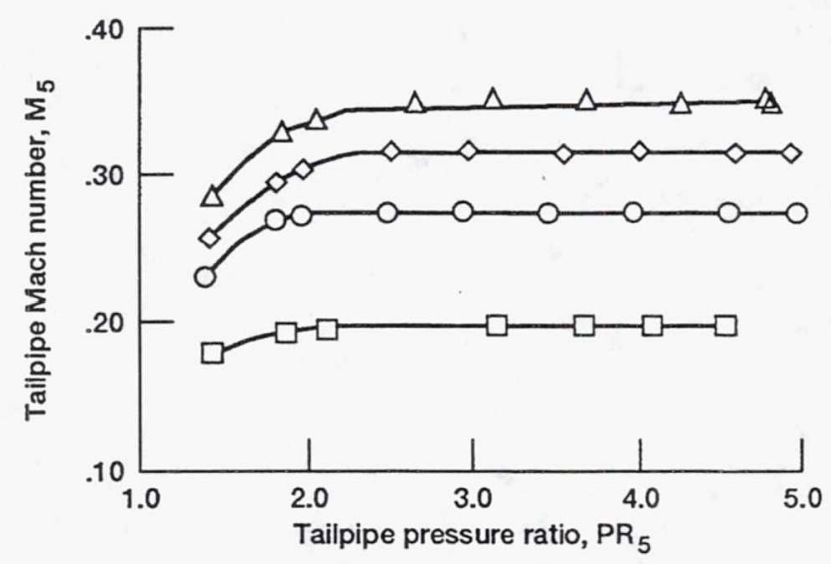

(b) Tailpipe Mach number.

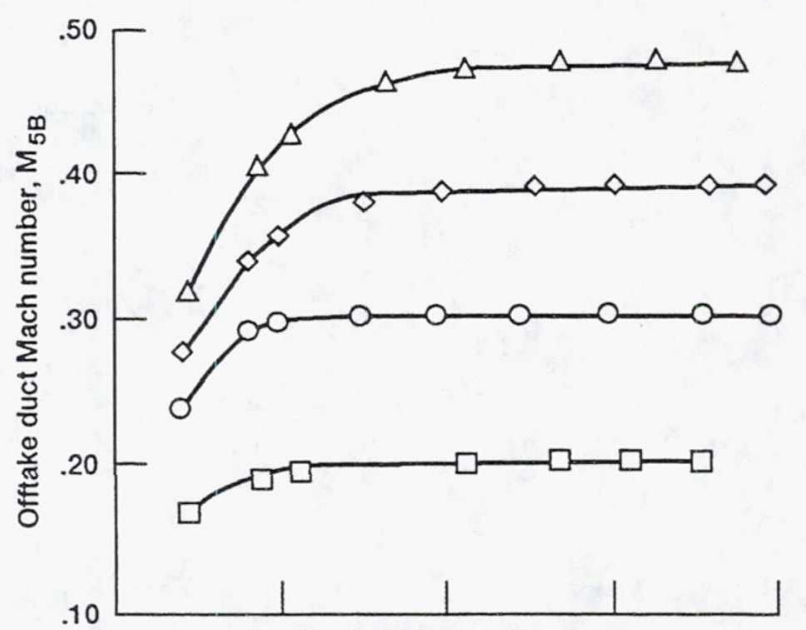

(c) Offtake duct Mach number.

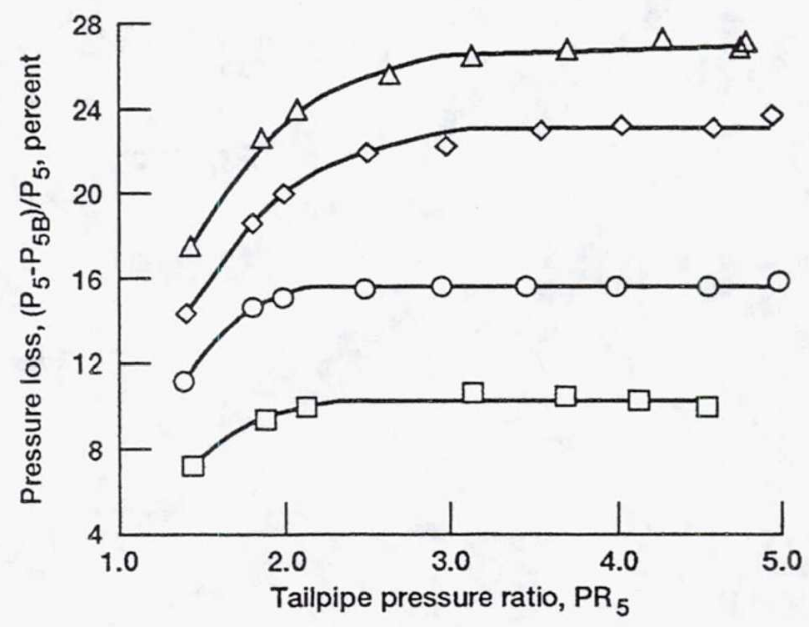

(d) Pressure loss to Station $5 B$.

Figure 13.-Performance of model without centerbody. 


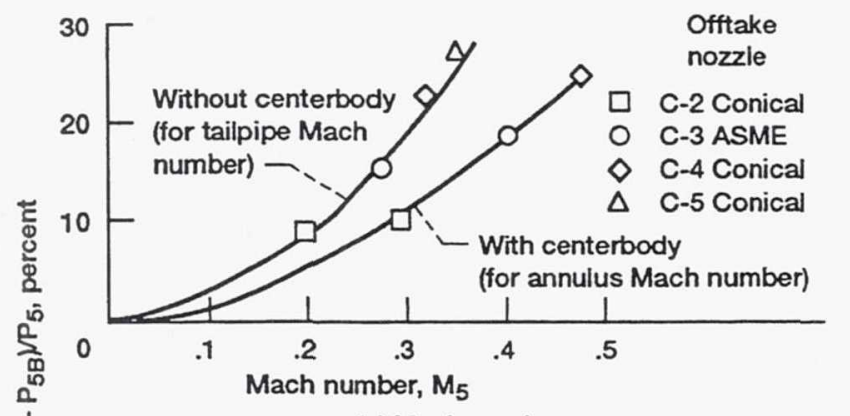

(a) Mach number.

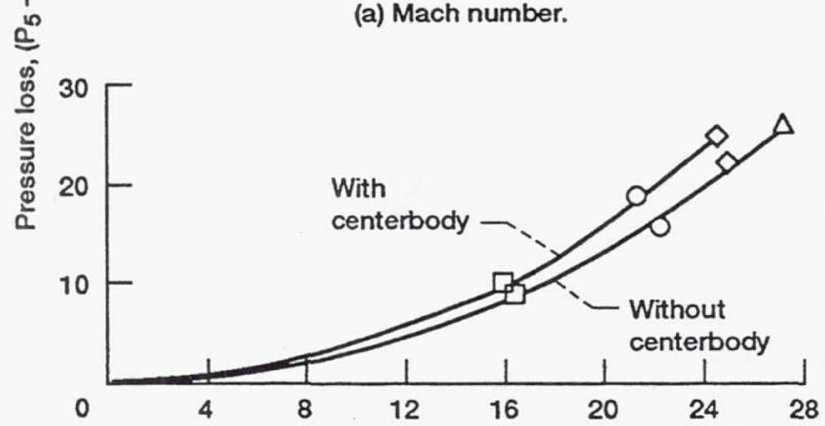

Airflow referred to Station $5,\left(\frac{w \sqrt{\theta}}{\delta}\right)_{5, \mathrm{ch}}, \mathrm{lb} / \mathrm{sec}$

(b) Airflow.

Figure 14.-Pressure loss to end of offtake duct for choked offtake nozzle flow.

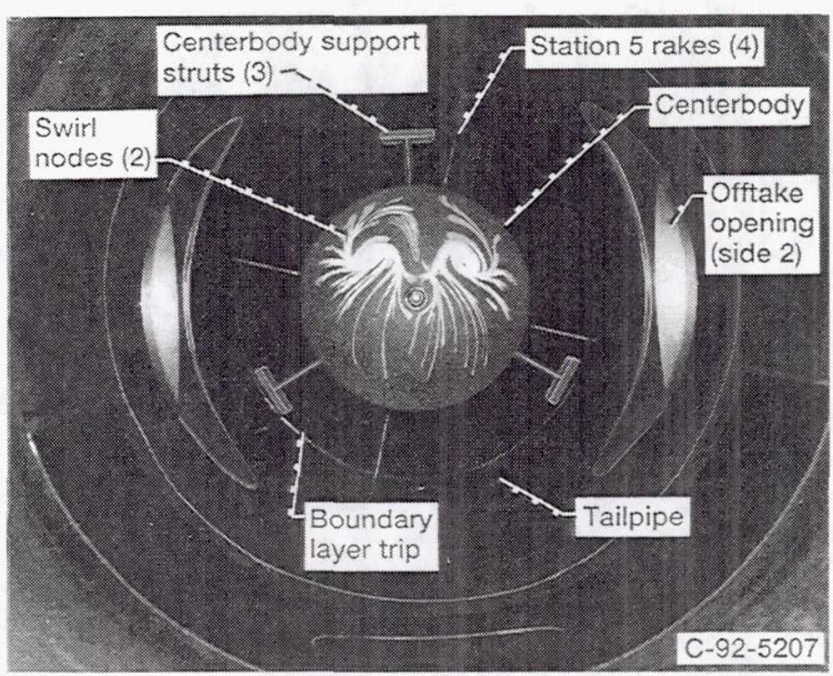

(a) Looking forward on tailpipe axis.

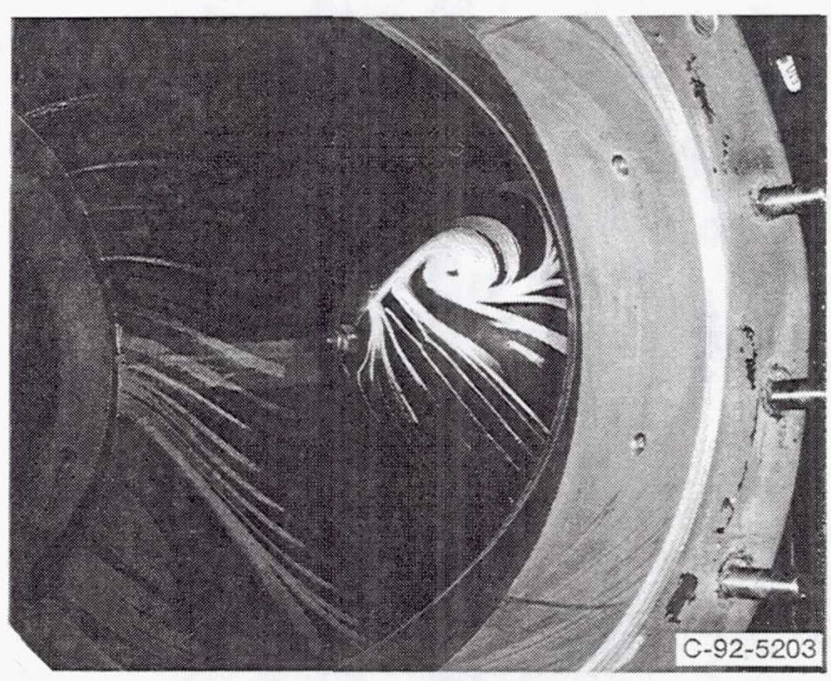

(b) Looking through side 2 opening.

Figure 15.-Flow visualization paint streaks on centerbody of basic model. 


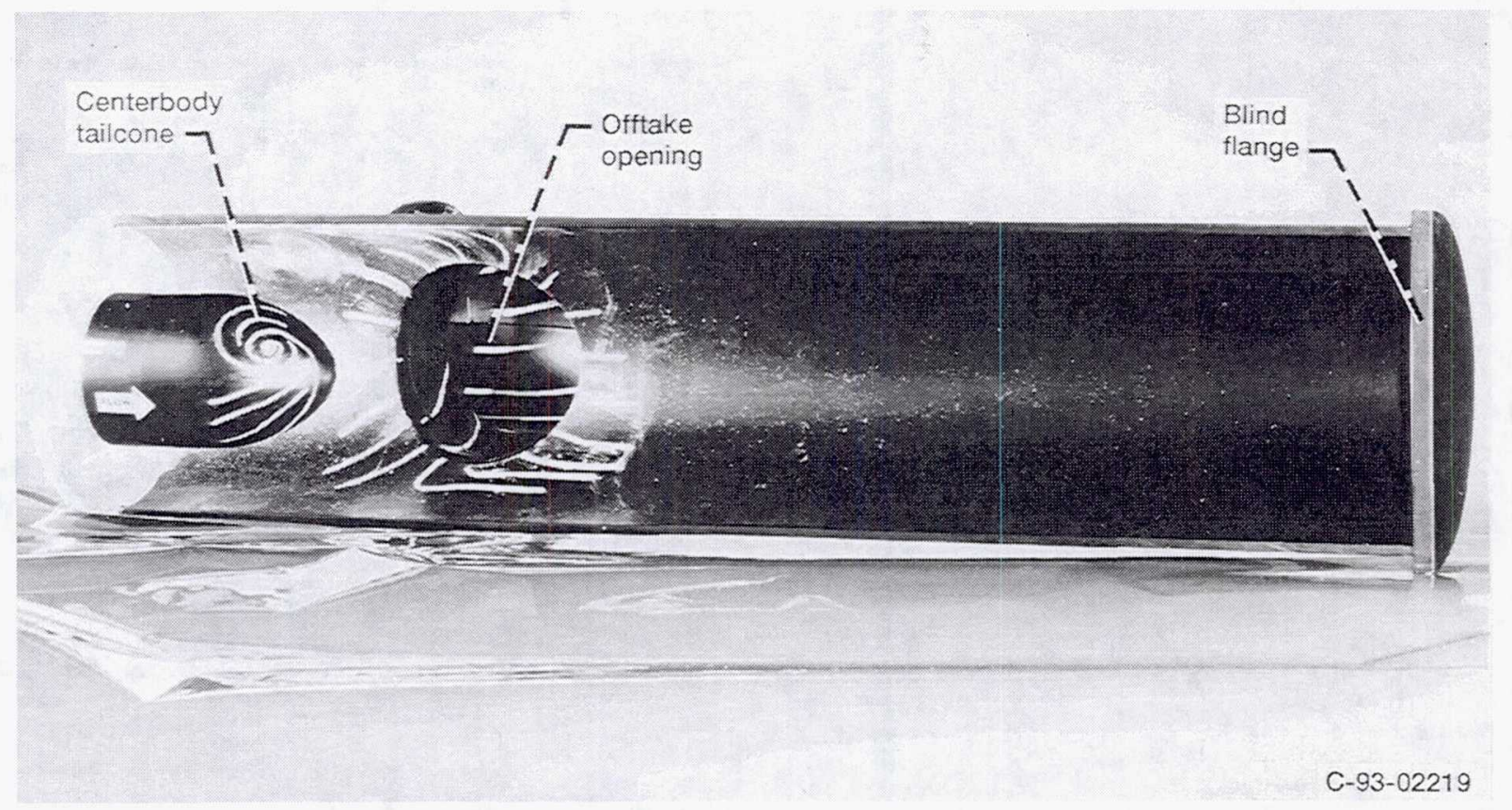

(a) Tailpipe cut on plane of symmetry.

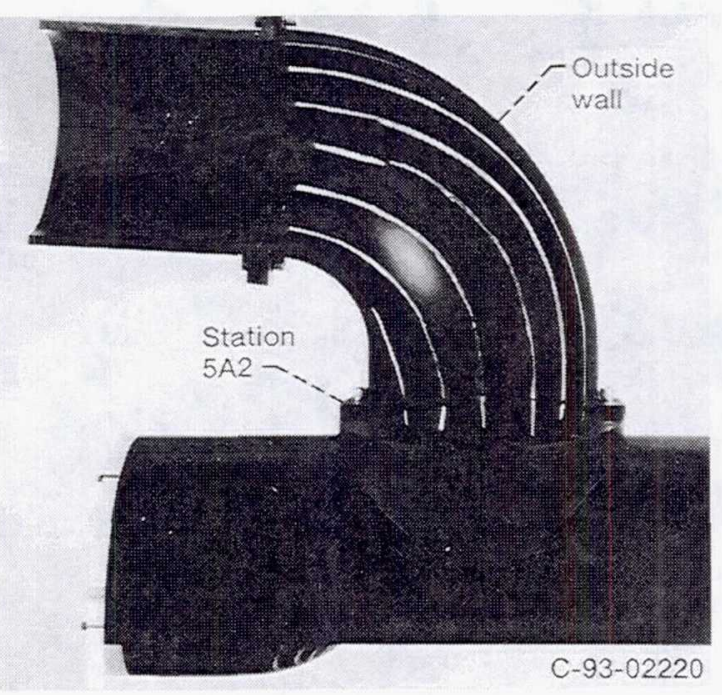

(b) Top half of offtake elbow removed (side 2).

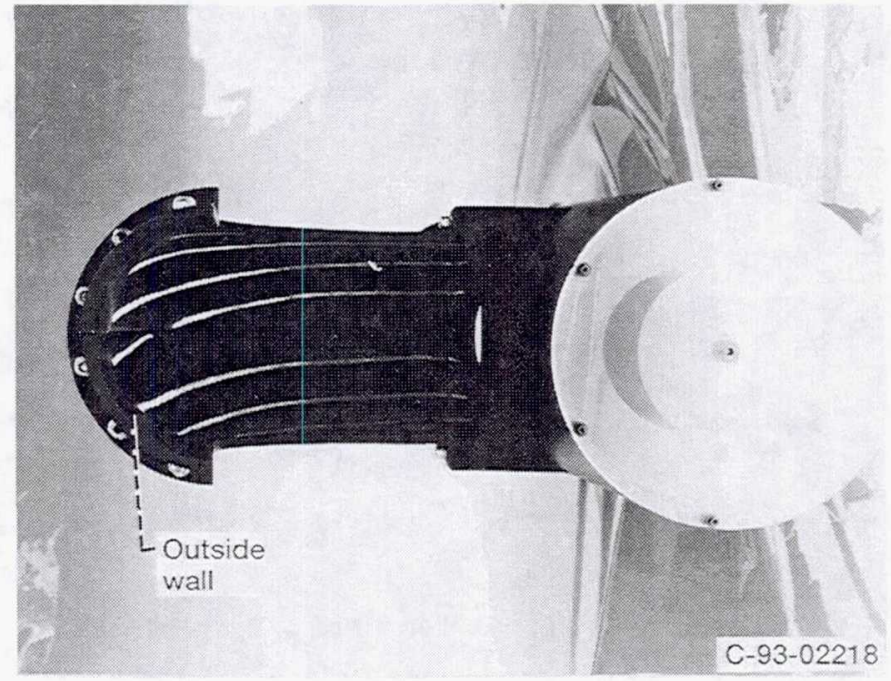

(c) Inside half of offtake elbow removed (side 2).

Figure 16.-Flow visualization streaks on scale mockup of basic model. 


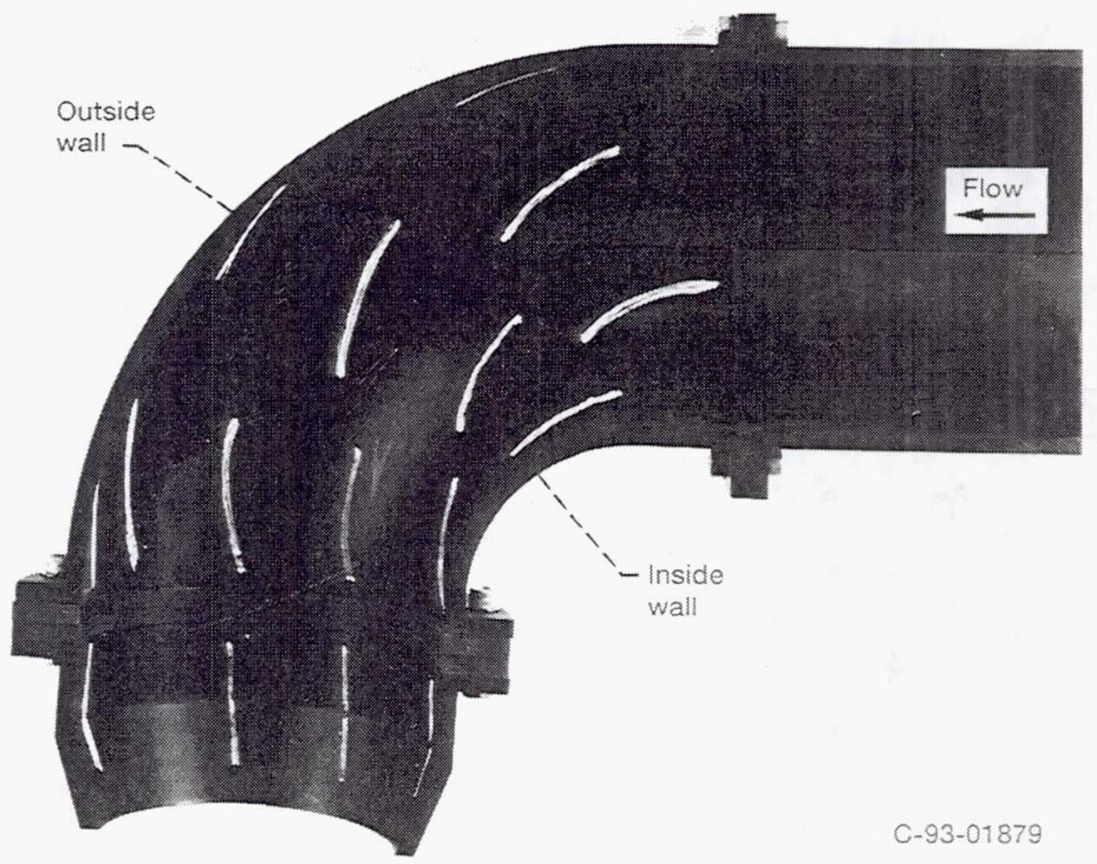

(a) Elbow cut on plane of symmetry.

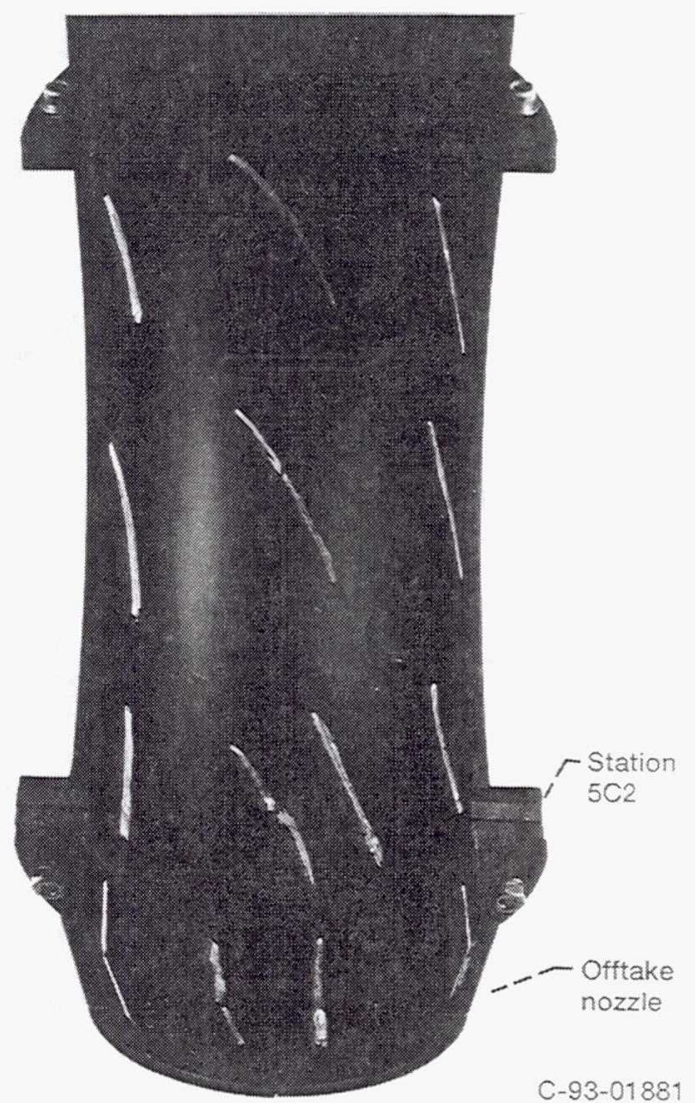

(b) Outside wall (inside wall removed).

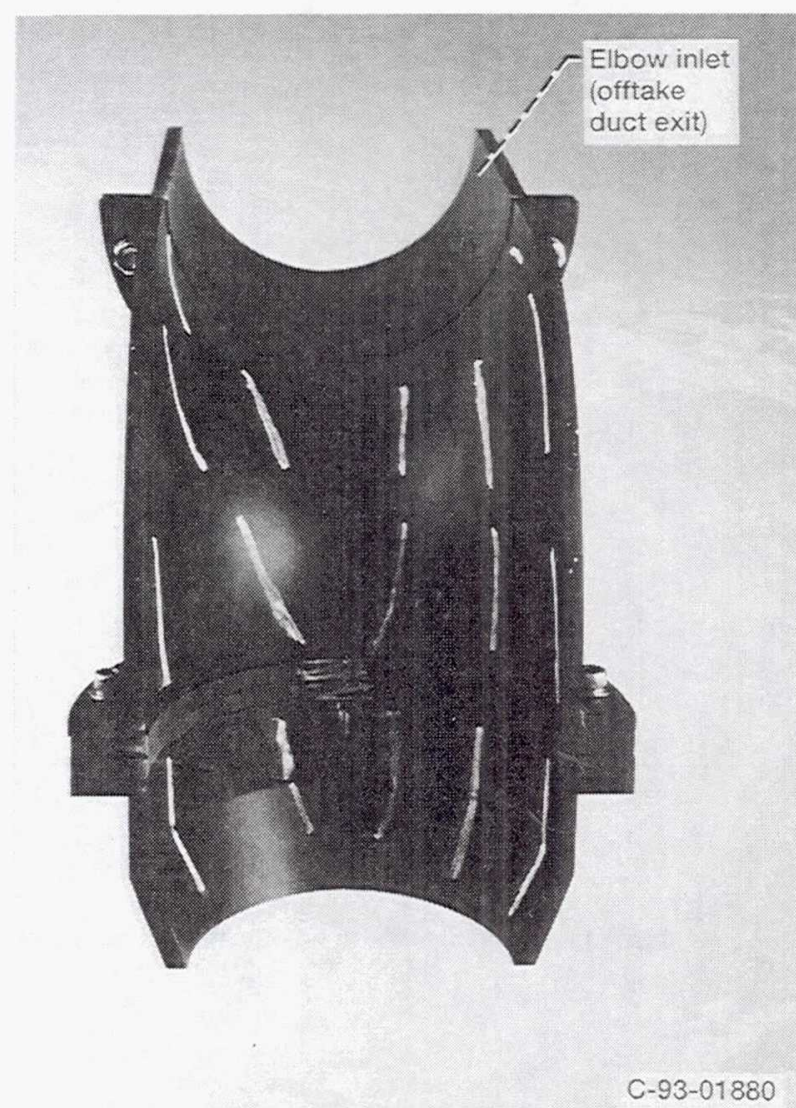

(c) Inside wall (outside wall removed).

Figure 17.-Flow visualization paint streaks around downturn elbow in side 2. 

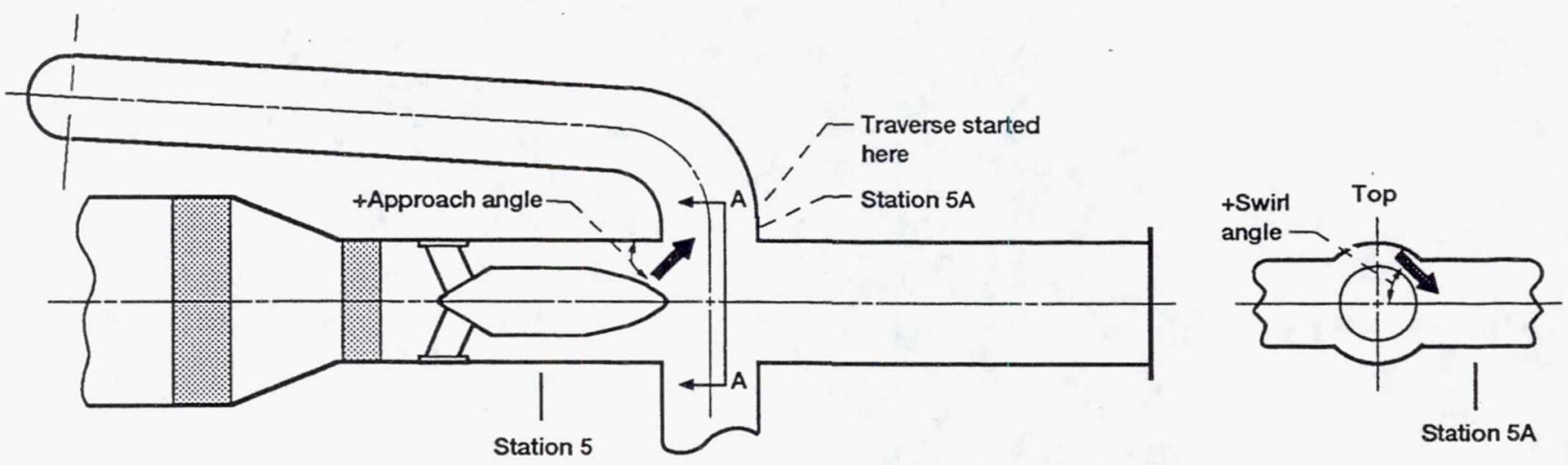

A-A

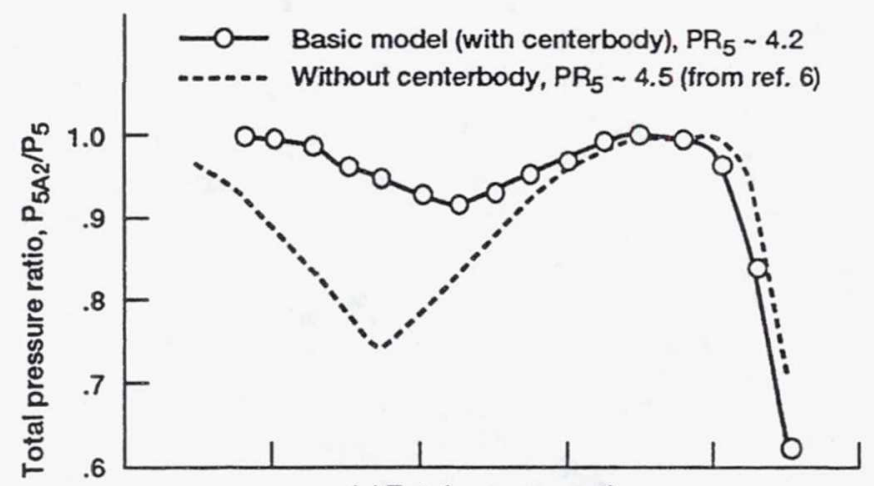

(a) Total pressure ratio.

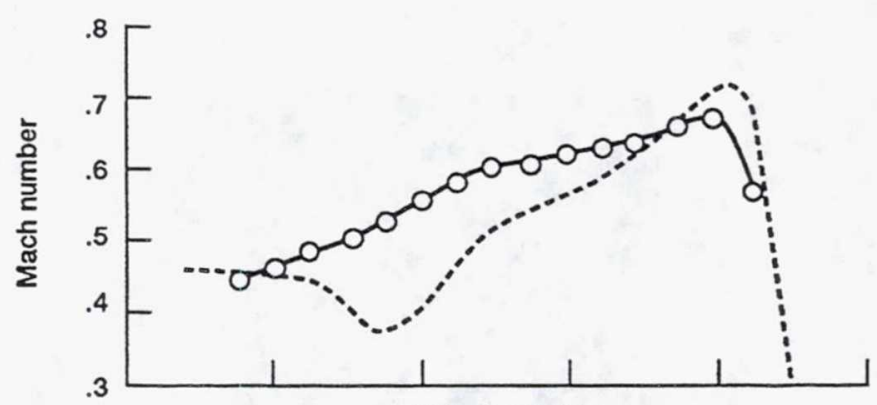

(b) Mach number.

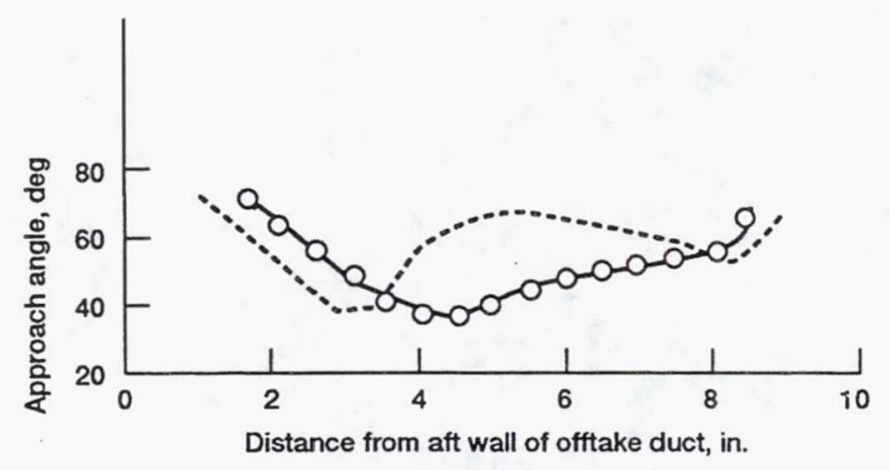

(c) Approach angle.

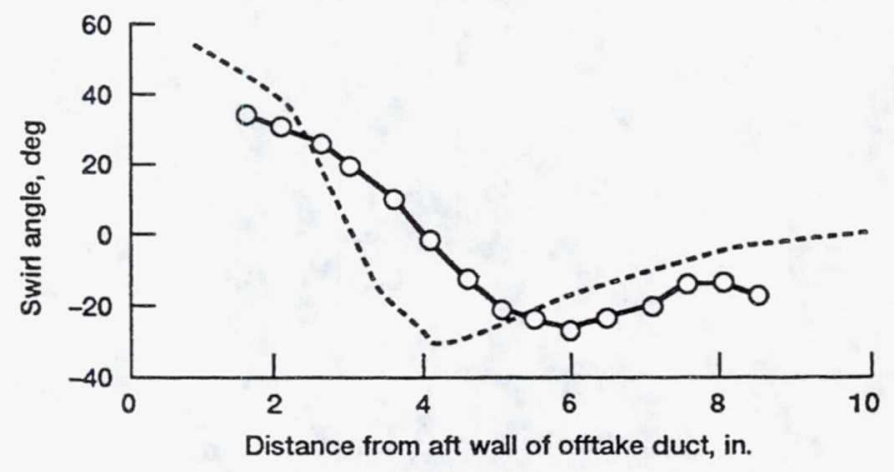

(d) Swirl angle.

Figure 18.-Flow conditions on offtake duct horizontal centerline at elbow entrance (Station 5A). C-3 offtake nozzles. 


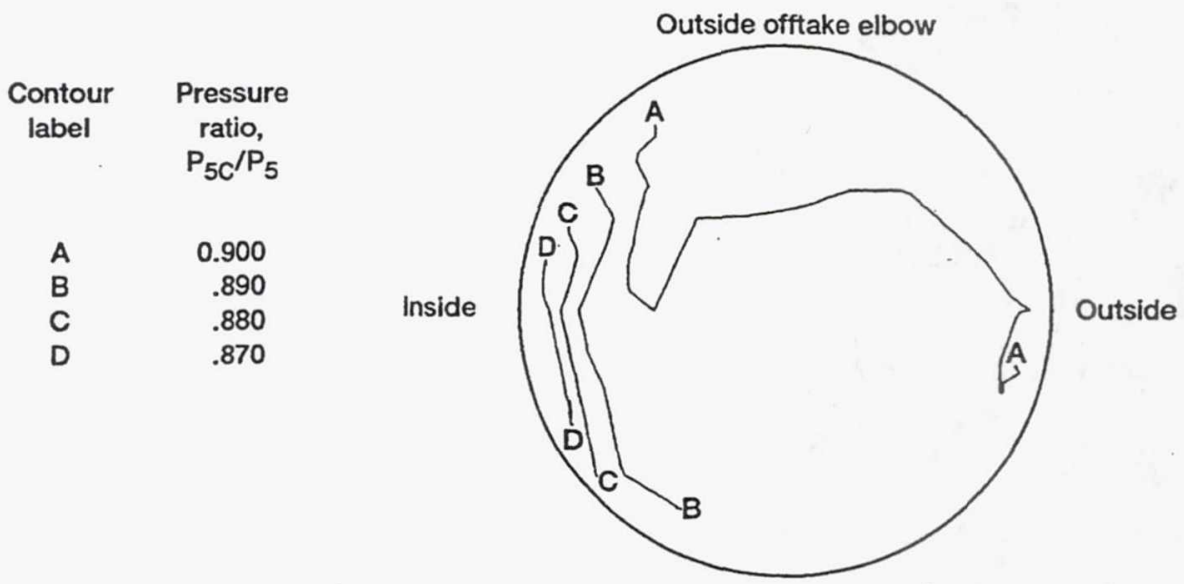

(a) $\mathrm{C}$-2 offtake nozzles; $\mathrm{PR}_{5}=4$; Station $5 \mathrm{~B} 2$ distortion $=1.8$ percent; Station $5 \mathrm{C} 2$ distortion $=5.6$ percent .

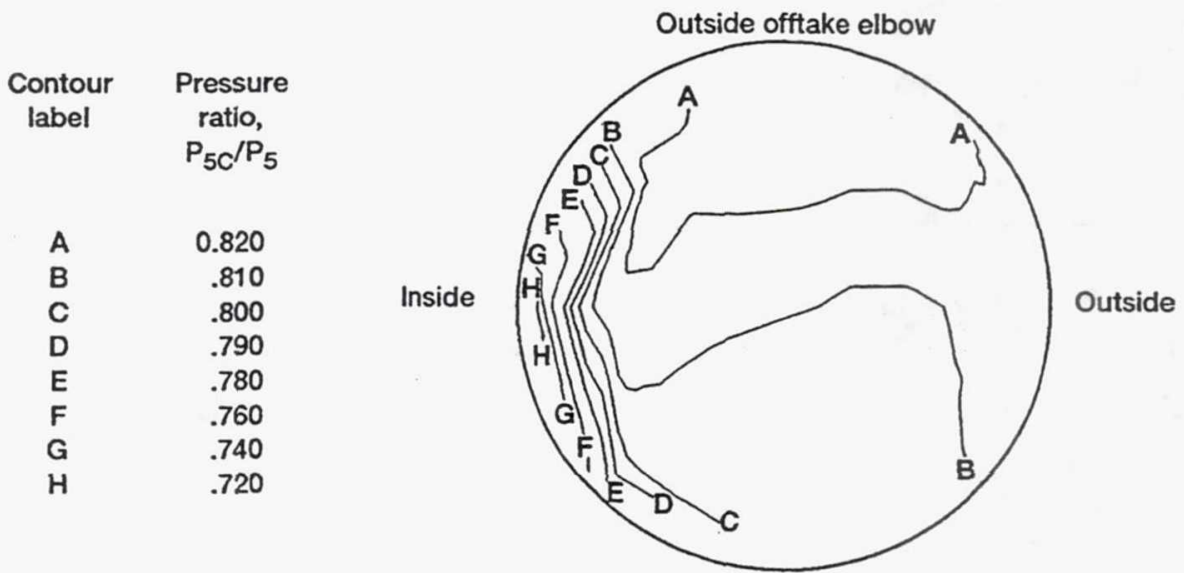

(b) C-3 offtake nozzles; $\mathrm{PR}_{5}=3.5$; Station $5 \mathrm{~B} 2$ distortion $=4.7$ percent; Station $5 \mathrm{C} 2$ distortion $=15.0$ percent.

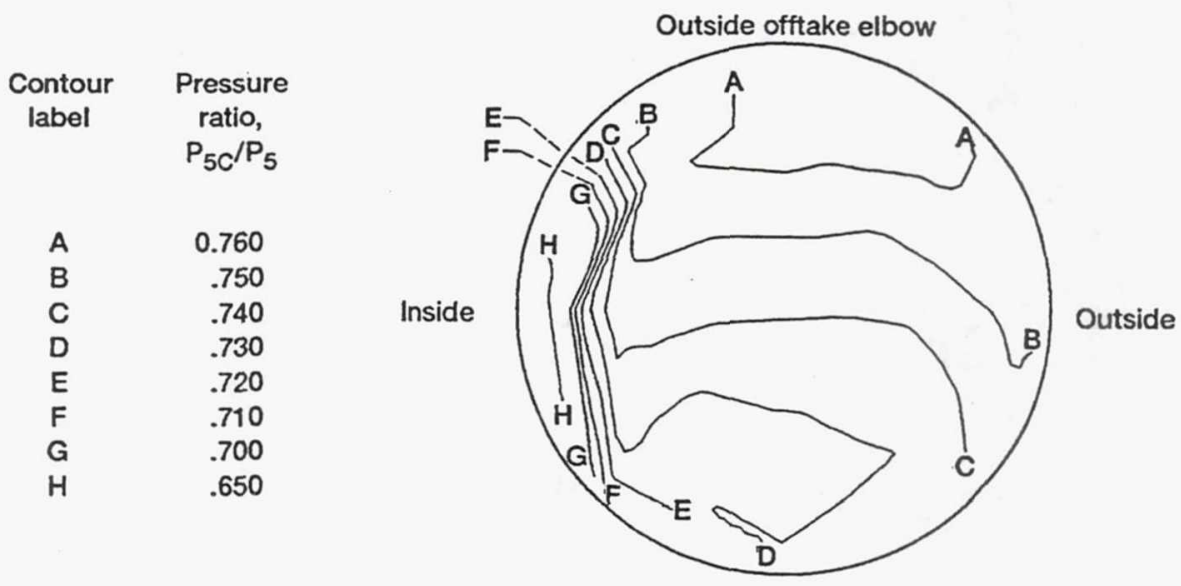

(b) $\mathrm{C}-4$ offtake nozzles; $\mathrm{PR}_{5}=3.0$; Station $5 \mathrm{~B}$ distortion $=7.9$ percent; Station $5 \mathrm{C}$ distortion $=19.2$ percent.

Figure 19.-Total-pressure contours at Station $5 \mathrm{C} 2$ (final downtum elbow exit side 2). View is looking upstream into the flow. 
Public reporting burden for this collection of information is estimated to average 1 hour per response, including the time for reviewing instructions, searching existing data sources, gathering and maintaining the data needed, and completing and reviewing the collection of information. Send comments regarding this burden estimate or any other aspect of this collection of information, including suggestions for reducing this burden, to Washington Headquarters Services, Directorate for Information Operations and Reports, 1215 Jefferson Davis Highway, Suite 1204, Arlington, VA 22202-4302, and to the Office of Management and Budget, Paperwork Reduction Project (0704-0188), Washington, DC 20503.

\begin{tabular}{|l|c|c} 
1. AGENCY USE ONLY (Leave blank) & $\begin{array}{c}\text { 2. REPORT DATE } \\
\text { June } 1993\end{array}$ & $\begin{array}{r}\text { 3. REPORT TYPE AND DATES COVERED } \\
\text { Technical Memorandum }\end{array}$
\end{tabular}

\section{TITLE AND SUBTITLE}

Effects of Flow-Path Variations on Internal Reversing Flow in a Tailpipe Offtake Configuration for ASTOVL Aircraft

6. AUTHOR(S)

Jack G. McArdle and Barbara S. Esker

\section{PERFORMING ORGANIZATION NAME(S) AND ADDRESS(ES)}

National Aeronautics and Space Administration

Lewis Research Center

Cleveland, Ohio 44135-3191

9. SPONSORING/MONITORING AGENCY NAME(S) AND ADDRESS(ES)

National Aeronautics and Space Administration

Washington, D.C. 20546-0001
WU-505-68-32
5. FUNDING NUMBERS REPORT NUMBER

E-7643

\section{SUPPLEMENTARY NOTES}

Prepared for the 29th Joint Propulsion Conference and Exhibit cosponsored by the AIAA, SAE, ASME, and ASEE, Monterey, California, June 28-30, 1993. Responsible person, Jack G. McArdle, (216) 433-3962.

12a. DISTRIBUTION/AVAILABILITY STATEMENT

12b. DISTRIBUTION CODE

Unclassified - Unlimited

Subject Category 07

13. ABSTRACT (Maximum 200 words)

A one-third-scale model of a generic tailpipe offtake system for an advanced short takeoff, vertical landing (ASTOVL) aircraft was tested at the NASA Lewis Research Center Powered Lift Facility. The basic model consisted of a tailpipe with a centerbody to form an annulus simulating turbine outflow with no swirl; twin offtake ducts with elbows at the ends to turn the flow to a downward direction; flow control nozzles at the ends of the elbows; and a blind flange at the end of the tailpipe to simulate a closed cruise nozzle. The offtake duct-to-tailpipe diameter ratio was 0.74 . Modifications of a generic nature were then made to this basic configuration to measure the effects of flow-path changes on the flow and pressure-loss characteristics. The modifications included adding rounded entrances at the forward edges of the offtake openings, blocking the tailpipe just aft of the openings instead of at the cruise nozzle, changing the location of the openings along the tailpipe, removing the centerbody, and varying the Mach number (flow rate) over a wide range in the tailpipe ahead of the openings by changing the size of the flow control nozzles. The tests were made with unheated air at tailpipe-to-ambient pressure ratios from 1.4 to 5. Results are presented and compared with performance graphs, total-pressure contour plots, paint streak flow visualization photographs, and a flow-angle probe traverse at the offtake entrance.

14. SUBJECT TERMS

SSTOVL; Exhaust systems; Propulsion systems; Tailpipe offtakes

15. NUMBER OF PAGES

23

16. PRICE CODE

$\mathrm{A03}$

\begin{tabular}{l|c|c|}
\hline $\begin{array}{l}\text { 17. SECURITY CLASSIFICATION } \\
\text { OF REPORT } \\
\begin{array}{c}\text { Unclassified } \\
\text { Un THIS PAGE } \\
\text { Unclassified }\end{array}\end{array}$ & $\begin{array}{c}\text { 18. SECURITY CLASSIFICATION } \\
\text { OF TECURITY CLASSIFICATION } \\
\text { OF ABSTRACT } \\
\text { Unclassified }\end{array}$
\end{tabular}

